University of Nebraska - Lincoln DigitalCommons@University of Nebraska - Lincoln

1996

\title{
Describing and Comparing Archaeological Spatial Structures
}

LuAnn Wandsnider

lwandsnider1@unl.edu

Follow this and additional works at: http://digitalcommons.unl.edu/anthropologyfacpub

Part of the Archaeological Anthropology Commons, and the Remote Sensing Commons

Wandsnider, LuAnn, "Describing and Comparing Archaeological Spatial Structures" (1996). Anthropology Faculty Publications. 70.

http://digitalcommons.unl.edu/anthropologyfacpub/70

This Article is brought to you for free and open access by the Anthropology, Department of at DigitalCommons@University of Nebraska - Lincoln. It has been accepted for inclusion in Anthropology Faculty Publications by an authorized administrator of DigitalCommons@University of Nebraska Lincoln. 


\title{
Describing and Comparing Archaeological Spatial Structures
}

\author{
LuAnn Wandsnider \\ Department of Anthropology, University of Nebraska-Lincoln, \\ Lincoln, Nebraska 68588-0368
}

\begin{abstract}
Quantitative archaeological spatial analysis today is radically different from that introduced more than 20 years ago. Today spatial analysis is couched in more general formational terms that include earlier functional pursuits. Today spatial analysts (1) focus on individual formationally sensitive artifact or element attributes, rather than on types; (2) use distributional rather than partitive methods and techniques; (3) consider a suite of such attributes to construct the formational history of archaeological deposits; and, least commonly, (4) undertake comparative spatial analysis. An elaboration of the latter tactic is proposed here, that of characterizing spatial structure in terms of structural elements (or "grid cells") and relationships among those elements. This proposal is illustrated through the analysis of five well-known ethnoarchaeological sites with different formational histories. The illustration focuses on the formational process of site maintenance and relies on the relative frequencies of small and large artifacts to monitor the operation of that process. Structural descriptors describe the configuration of grid cells with different artifact size profiles in formationally meaningful terms. Importantly, these descriptors enable the rigorous comparison of spatial structure among and between ethnoarchaeological and archaeological deposits.
\end{abstract}

Keywords: site structure, spatial analysis, ethnoarchaeology, hunter-gatherers

\section{Introduction}

Site structure is the patterned distribution of artifacts, features, and other materials in site space. For more than 20 years, quantitative spatial analysis has been used to describe and interpret these arrangements of archaeological 
materials at hunter-gatherer sites. Over this span of time, the practice of archaeological spatial analysis has become increasingly sophisticated. Even so, as various researchers (Blankholm, 1991, pp. 23-26; Kroll and Price, 1991, pp. 1-6, 301-305; O'Connell, 1987, p. 106, 1993, p. 7; Whallon, 1978, pp. 2728,1984 , p. 242) have observed over this same time span, site structural analyses have generated little new knowledge about archaeological deposits or the past, although certainly we have a better idea of what they cannot tell us.

This lack of success has been repeatedly charged to a lack of congruence between our methods of characterization and our understanding of the formation of archaeological deposits. A more serious problem, however, has recently been identified by O'Connell (1995). He cites the lack of a theory of site structure that both integrates the many disparate ethnoarchaeological observations on site structure and is useful for interpreting archaeological deposits. Without basic, tractable, middle-range theory, the ethnoarchaeologically observed relationships between behaviors and site structure patterns can only be applied to archaeological deposits analogically or in a cautionary fashion [see Yellen (1977) for a similar observation].

In this present state, O'Connell (1995, p. 211) argues, it is unlikely that we can learn little new or interesting about the past from site structural studies. In the present paper, I attempt to deal with both issues. Considering first the more serious charge, that site structure studies lack a theoretical foundation, I disagree with $\mathrm{O}^{\prime}$ Connell's assessment. In fact, we have and require many such bodies of theory, which relate process and spatial pattern. These bodies of theory, however, are neither equally robust nor, in their application to archaeological situations, equally tractable. Therefore, multiple bodies of theory associated with multiple bodies of spatial data must be used in tandem (Wylie, 1989). For this reason, comparative spatial analysis will prove essential for taking information from structural studies beyond analogy and cautionary tales.

Second, only recently have we come to employ methods and techniques that are congruent with the consensus understanding of the archaeological record and with theoretical goals for interpreting that record, as shown by an historical review of site structure. What is lacking, however, is a means for carrying out rigorous comparative spatial analyses, which I argue below is critical for spatial analysis to contribute unique and interesting information about the past In the following, I illustrate the construction and use of tools for describing archaeological spatial structure in theoretically based units and in comparative terms.

Some (Kroll and Price, 1991, p. 5; O'Connell, 1993, p. 21; Tipps, 1993) would restrict site structure studies to those deposits judged a priori to yield information on structure. I see such studies, however, as broadly applicable 
to archaeological deposits in general. Thus, I begin this essay by attempting to justify this perspective, since both theory and method follow from it.

\section{Archaeological Spatial Structure: Role and Middle-Range Theory}

Archaeological deposits may be patterned in many ways and, indeed, may even have a random spatial pattern. As noted by O'Connell (1995, p. 7; see also Kintigh and Ammerman, 1982, p. 33), however, when archaeologists talk about "site structure," they usually mean the patterning in artifacts and features created by a group of people at a site during a continuous occupation over the space of days or weeks and, less frequently, months, or years. Moreover, they usually refer to deposits associated with "occupation surfaces" or "living floors." And, site structural studies are commonly recommended for those sites where "structure... is clear to the naked eye..." (Kroll and Price, 1991, p. 5).

Humans, however, are but one of many agents that introduce patterning into archaeological deposits (see below). By restricting site surveys to those areas where sites were expected, the then current, but incomplete knowledge of site locations was reinforced. Similarly, by limiting site structure studies to those archaeological deposits with obvious and familiar patterning, the possibility of learning about the practice of structuring behaviors by hominids is denied, Certainly, this is one of the reasons why the patterned remains at hominid sites have been investigated (Kroll and Isaac, 1984; Binford, 1983).

Beyond learning about the evolution of familiar structuring behaviors in hominids, there are other compelling reasons for investigating the spatial structure of deposits, whether associated with living floors or not. The patterns introduced into archaeological deposits by natural processes, or culturally, through processes such as dumping or reoccupation, also provide important information about the role of that location in the systemic and situational use of the landscape (Binford, 1982). For example, Smith and colleagues (1995) rely on site structure analyses to interpret the occupation histories of two Late Prehistoric sites in southwest Coming. With little number crunching except to perhaps isolate high density areas, and also relying on conjoining artifacts, they interpret 48SW7107 as a single occupation, short-term residence created by a frequently moving group and 48SW270 as formed through multiple, longer-term occupations during which heavy processing took place. Given many more both simple and palimpsest deposits in southwest Wyoming during the Late Prehistoric, a detailed portrait of mobility and settlement over the span of several generations may 
emerge. This regional, transgenerational picture may eventually contain, for example, locations with single, short-term occupations on stable surfaces along with single, short-term occupations on aggrading surfaces, frequent medium-term reoccupations on eroding surfaces, and so forth.

And, beyond a concern for learning about the organization and functioning of the past system of adaptation, this regional portrait provides one view of the selective regime within which human evolution and culture change occurred (Rossignol, 1992; Wandsnider, 1992).

Importantly, except in a few areas with high-resolution chronologies, NO standard chronological indicators will ever be of high enough resolution and reliability to establish individual occupation events that make up these occupational histories. Only through the spatial analysis of archaeological deposits can this kind of formational history be reckoned (Wandsnider, 1992).

An historical review of archaeological site structure studies (see below) shows, I believe, the emergence of this appreciation for the information contained by both fine- and coarse-grained deposits (Binford, 1978a, 1980) with, respectively, high and low temporal resolution. For this reason, I have chosen to frame the following discussion in terms of archaeological spatial structure, rather than archaeological site structure. Expanding beyond the interpretation of site structure in terms of human behavior, the proximate goal of spatial structure studies I take as grounding inferences about formational history.

By extending the scope of the discussion in this way, we admit that spatial structuring is owed to many agents, some of greater interest than others. The problem still remains of how to infer which processes were responsible for generating the observed spatial patterning. To this end, many bodies of middle-range theory - one for each contributing processare required. [Schiffer (1987) has summarized some of these bodies of theory in terms of their formal content; their spatial consequences still need elaboration.]

Not all bodies of theory are equal, however. In addition to other aspects, they vary in terms of the complexity of the relationship specified between process and pattern. Some, like the theory of slope mechanics, which describes the differential movement of objects on slopes, are simple with just a couple of parameters - degree of incline, friction, size of object - that influence the resulting pattern. Thus, Rick (1976), in his investigation of slope deposits at the Peruvian cave of Ccurimachay, needed to monitor only a few variables to assess the degree to which slope processes were responsible for the spatial patterns observed at Ccurimachay.

Other theories relate complex systemic phenomena and complex 
archaeological phenomena. I suggest below, in contrast with O'Connell's (1995) assessment, that we do possess a theory of "site structure" and that it is of the latter variety. This theory, which relates cultural maintenance behavior and site structure, exists in a version of Schiffer's (1988) waste stream theory that Ronald Kneebone (1990) has recently recast in nonlinear thermodynamic terms. The theory is complex in that the relationship it specifies depends on many different parameters, as demonstrated by a great deal of ethnoarchaeological research. For example, the operation of site maintenance depends on whether activity spaces are sheltered or unsheltered, contain small or large quantities of debris, involve a single working person or a task group, and so forth. Importantly, archaeologically establishing the values of these parameters has proved a very challenging task, which O'Connell (1995, pp. 216-220) and other spatial analysts have highlighted.

Archaeological identification, meaning unequivocal, unambiguous inference (Binford, 1981b, pp. 21-30) of past process, is the most robust form of archaeological inference and yields maximally defensible statements about the past. Identification depends not only on middle-range theory that specifies the biconditional relationship between process and pattern (Wylie, 1992:35), but also on knowing the values of critical parameters stipulated by that theory. For most natural formation processes, with few parameter values to be established, their archaeological identification is relatively straightforward. [Here, the major problem of identifying that a particular process has occurred is that of equifinality, i.e., that several processes potentially result in deposits that are morphologically similar (Hodder and Orton, 1976, pp. 239240; Sullivan, 1992b)].

Theories that both contain multiple parameters and, most importantly, have parameter values that are difficult to establish, like the theory of "site structure" discussed below, cannot be used to make archaeological identifications, as defined above, I think it is this problem of application, rather than lack of theory per se, that has hampered archaeological site structure studies (cf. O'Connell, 1995).

For studies of archaeological spatial patterns to be useful, then, other, less robust, kinds of inference must be considered. In situations of this kind, Wylie (1989) has suggested an approach that relies on many inferential strands that together implicate certain interpretations and also deny other interpretations. By "tacking" the (hopefully) narrowing gap between possible and impossible interpretations, we approach an interpretation of spatial structure via means other than identification. Certainly, this mode of inference is complex and difficult, but, at present seems the only means available for inferring the operation of complex formation processes. 
Following Wylie, a two-pronged approach is suggested. First, by carrying out many structural analyses, each focusing on a different structural indicator and each yielding differentially incomplete information, a composite picture of formation history may nevertheless be constructed. Second, by comparing spatial patterns across a number of archaeological contexts, some of those difficult-to-establish contributing parameters can be held constant.

Seymour and Schiffer's (1987) analysis of Snaketown, Binford's (1987) analysis of an Alyawara camp, and other analyses discussed below illustrate this "tacking" solution. In the following, the focus is on enabling the second part of the approach, that is, developing analytic tools that permit the comparison of spatial structure.

Thus, the comparative analysis of archaeological spatial structure is essential for what it can tell us about the past configuration and use of the cultural landscape. As importantly, it is critical to archaeological interpretation when inference through identification cannot be sustained, as in the case of complex processes with parameters that are differentially knowable from the archaeological record.

Having offered these thoughts on the potential role of quantitative archaeological spatial analysis and on the imperative need for comparative spatial studies, I turn now to its actual practice.

\section{Archaeological Spatial Structure: Methodology and History}

More than 20 years ago, Robert Whallon $(1973,1974)$ pioneered the subdiscipline of quantitative archaeological spatial analysis, which proposed methods and techniques of analysis compatible with the then-current analytic goals. Since that time, goals, methods, and techniques have evolved dramatically, as recently emphasized in several excellent historical critiques of spatial analysis in archaeology (Blankholm, 1991; Gamble, 1991, pp. 1119; Kroll and Price, 1991, pp. 1-6). Over this span of 20 years, the critiquesespecially that by Kroll and Price-recognize several mutually reinforcing trends: the increasingly common practice of high resolution documentation of archaeological sites and wide availability of archaeological data amenable to spatial analysis; the contribution that actualistic studies have made to our evolving understanding of how site structure forms; and the growing sophistication of quantitative methods that make few assumptions about the statistical properties of archaeological assemblages.

The critiques recognize, too, that no one protocol has emerged that everyone agrees is THE BEST way to conduct spatial analysis. Indeed, Describing 
Archaeological Spatial Structures 325 some (Kent, 1987; Blankholm, 1991, pp. 48,52 ) contend that a single spatial analytic panacea is unlikely. Meanwhile, standards for other kinds of archaeological analysis-Blankholm (1991, p. 28) points to pollen analysis - do show a progression

In fact, as the following historical sketch attempts to show, there appears to be an emerging consensus in the assumptions, proximate goals, and practice of archaeological spatial analysis. Compatible with the above identified goal, that of inferring processes responsible for the formation of archaeological spatial structure, I see evidence for several analytic tactics that have come to be employed by archaeologists working with spatial data. These tactics include focusing explicit analytic attention on individual formationally sensitive artifact or element attributes, rather than on types, and using quantitative techniques that are distributional, rather than partitive.

Pertinent to the above-expressed concerns on the ability of spatial studies to ground inferences about the past, there is also evidence that spatial analysts have begun examining a suite of such attributes, both to constrain interpretations and to construct formational histories. Finally, some researchers also are beginning to undertake comparative analyses of spatial structure. In what follows, however, I suggest that these critical comparative efforts are hampered by the lack of consistently performing comparative techniques. I therefore propose an analytic remedy.

The following historical review attempts to support these statements.

\section{A Brief History}

Table I summarizes the widely available literature on site-scale archaeological spatial analysis for which authors included a discussion of theory and methods. This summary includes the assumptions of the author(s), i.e., whether their treatment conforms to a functional or formational view (both defined below) of archaeological deposits and their information content; the proximate goals they identified for their spatial analysis, e.g., to identify activity areas; the methods and techniques used, usually either partitive or distributional; and the analytic variables (artifact types, attributes, or other) on which they relied. Several trends in the practice of site structural studies are evident, as presented graphically in Figure 1.

In general, archaeological spatial analysis shows a lagged transformation from a functional view of archaeological site structure to a formational view of archaeological spatial structure. I use the term "view" to mean the interrelated set of assumptions that archaeologists make about how archaeological deposits come to be structured and the potential information content 


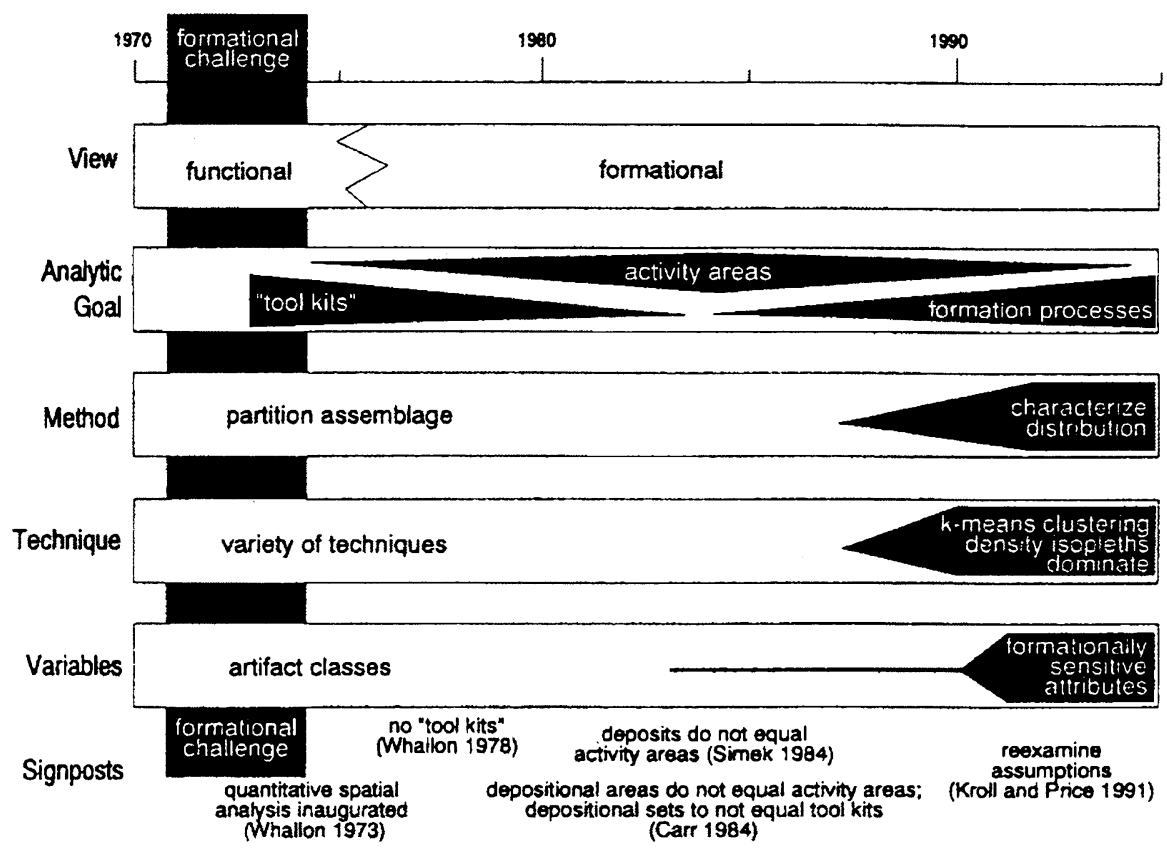

Figure 1. Trends in quantitative spatial analysis.

of that structure. By "functional view of site structure," I refer to that suite of assumptions held by early analysts of archaeological site structure recently summarized by O'Connell (1993, p. 9; 1995, p. 212), that humans at sites worked within discrete, exclusive, activity-specific areas; each activity was associated with a specific set of artifacts, i.e., a tool kit; activity specific artifacts were discarded at their use location along with debris; and artifact frequency varied directly with activity frequency. By "formational perspective," I refer to that view of both archaeological deposits and the past that emerged in the 1970s. In this view, both cultural and natural formation processes are acknowledged as responsible for the structure of archaeological deposits; information about their operation is assumed to be retrievable from the deposits.

By "lagged transformation," I mean that while the formational view was rapidly embraced by archaeologists, the full implications of this view for analytic goals and for selecting compatible methods, techniques, and analytic variables were not immediately appreciated. It is only in the 1990s that concepts, proximate goals, methods, techniques, and variables consistent with this view are widely employed in archaeological spatial analysis.

At its inception, quantitative spatial analysis of site assemblages had goals similar to those studies carried out without the assistance of quantitative analysis at, for example, Olduvai Gorge, Lazaret, and Star Carr, i.e., 


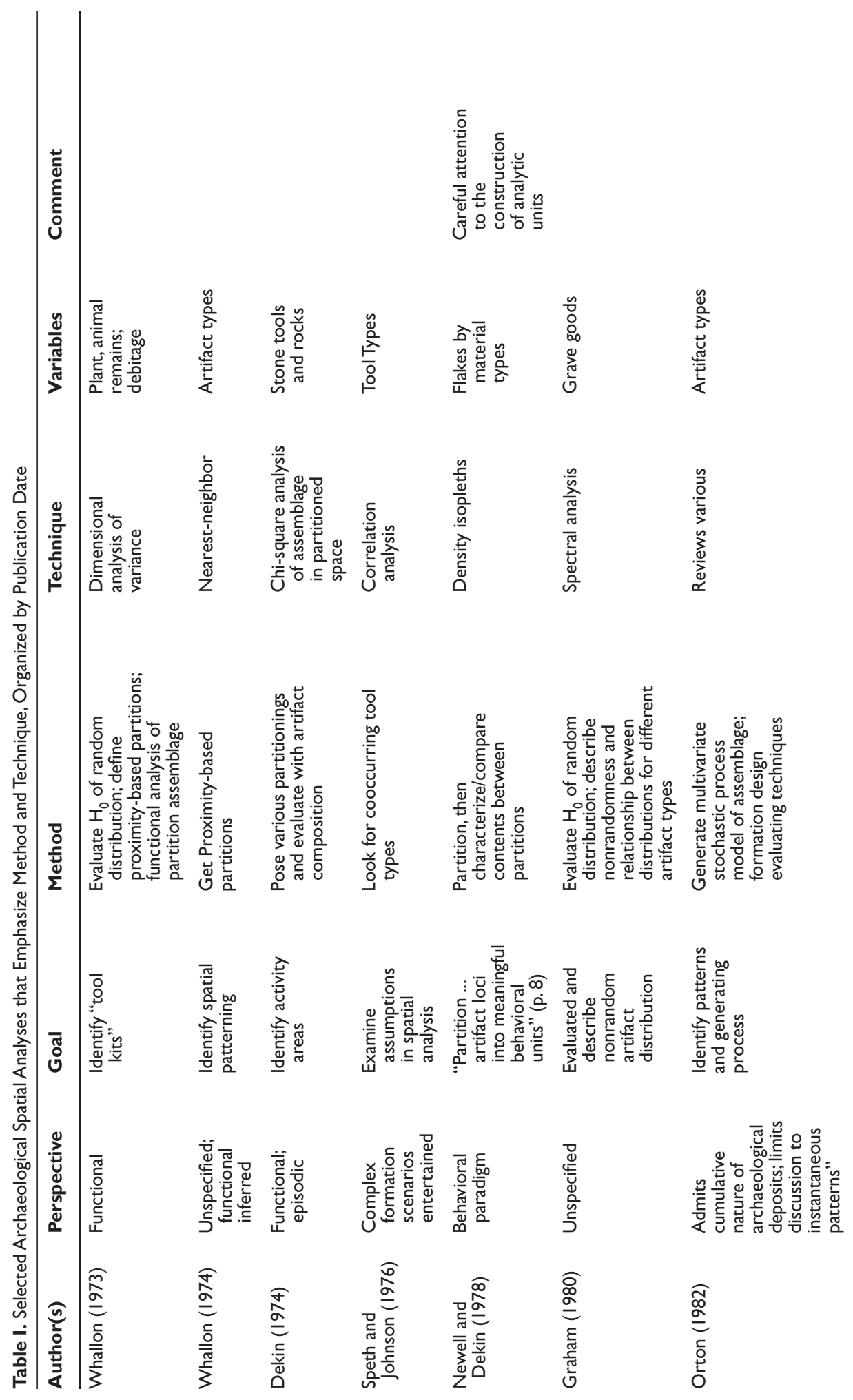




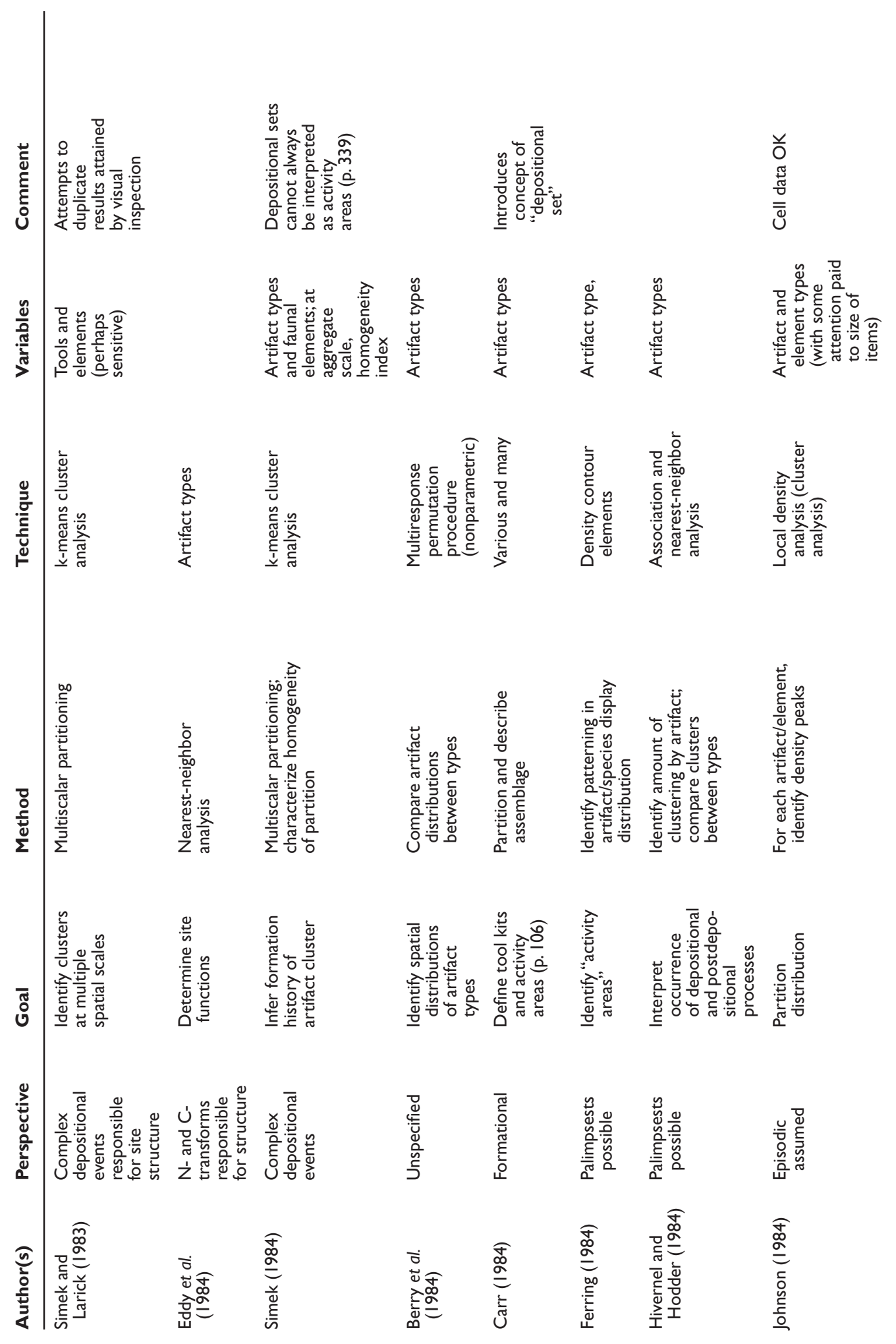




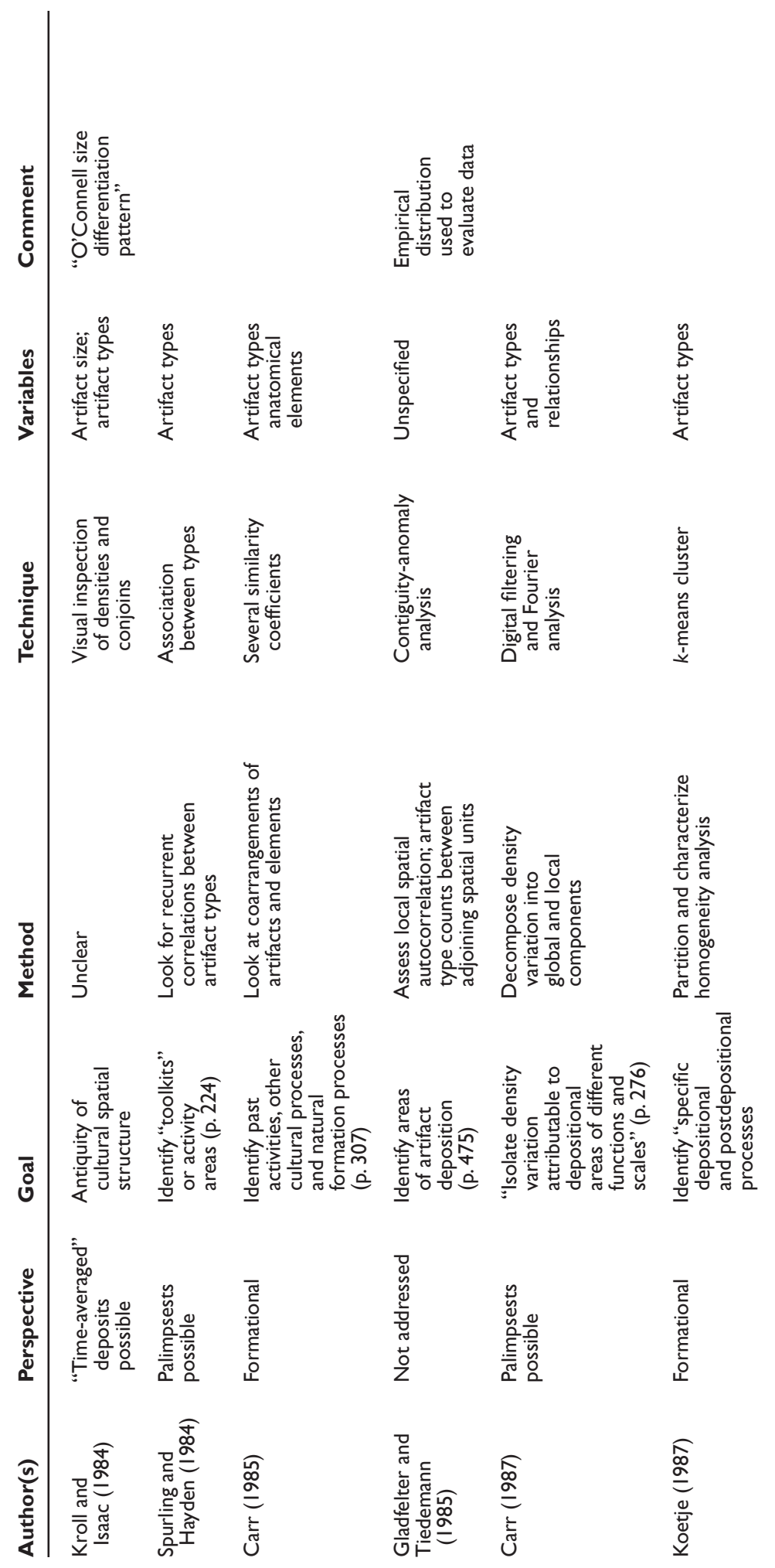




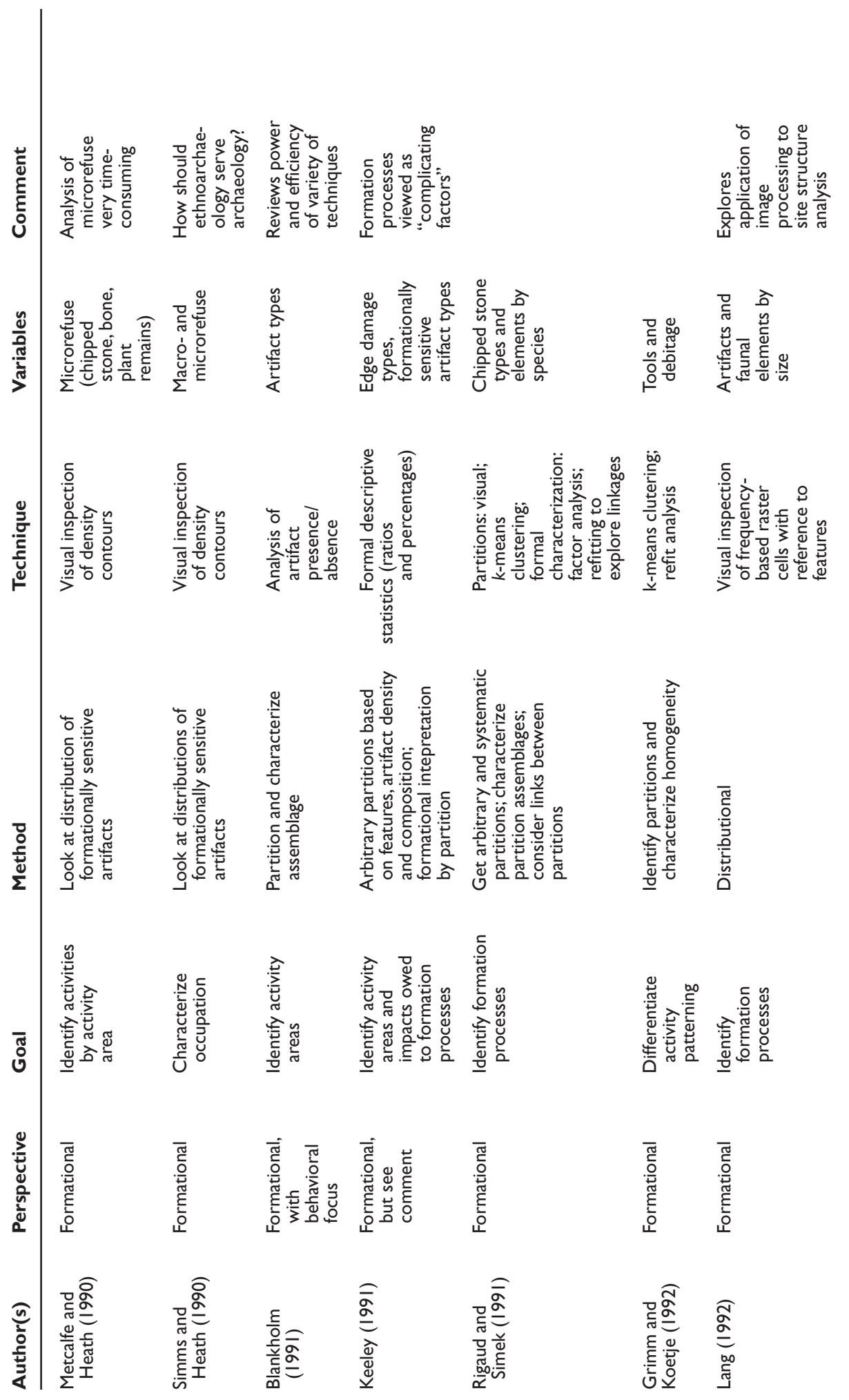


है

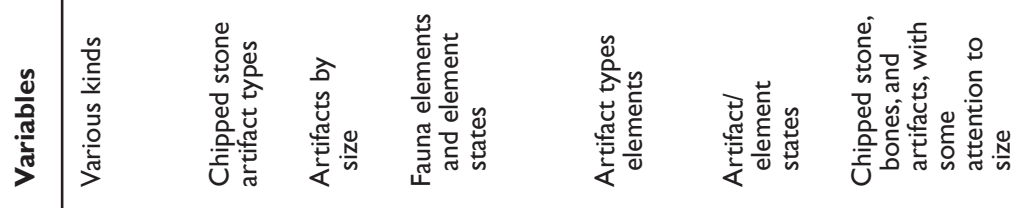

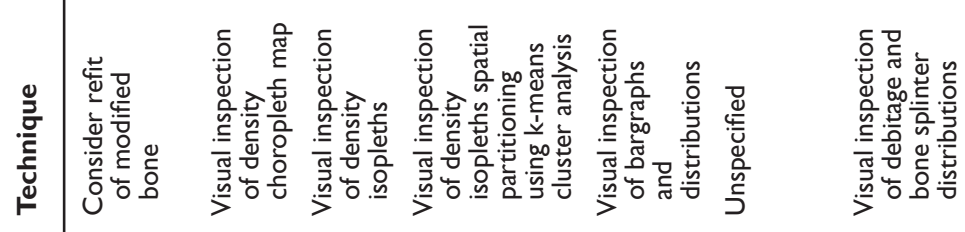

$\frac{0}{\frac{0}{\lambda}}$

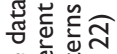

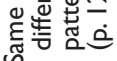

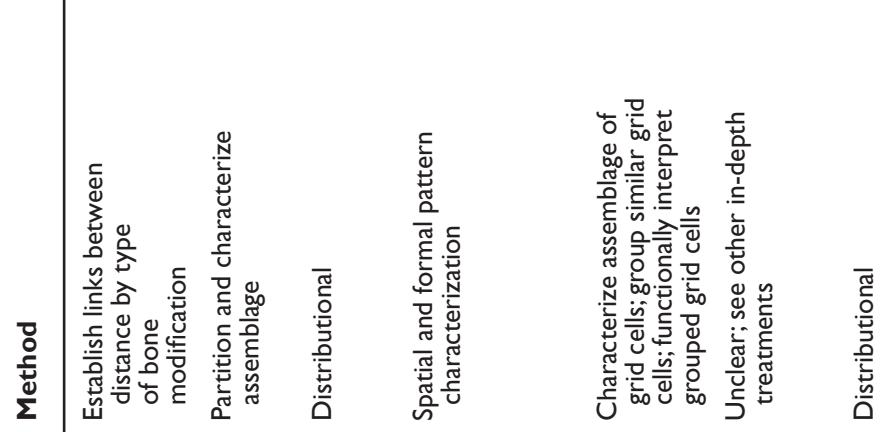

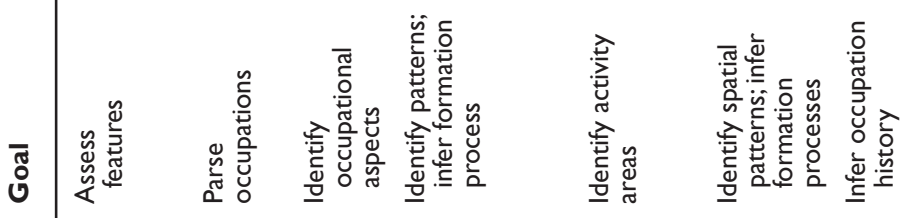

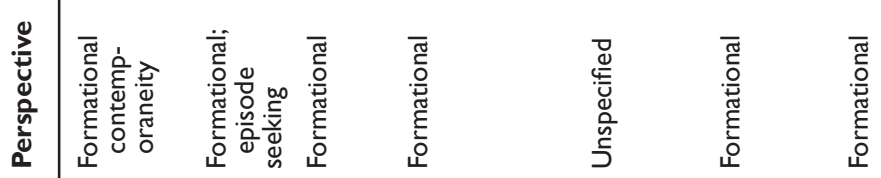

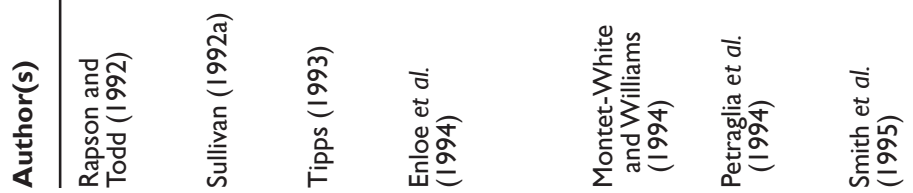


the definition of "tool kits" on occupation floors (Whallon 1973, 1974; quotes lending special emphasis cited by Whallon, 1973, Whallon, 1978; Speth and Johnson 1976) and, later, tool kits and activity areas (no quotes; Can*, 1984, p. 103). With this information, Robert Whallon (1973, p. 266) indicated, "[I]t is hoped that inferences concerning patterns of prehistoric human activity can be made by interpreting the "tool kits" in terms of then contents and their position on the occupation floors."

This statement does not reflect the larger goals of the early New Archaeologists who carried out much of this work, that of approaching an understanding of task and social group organization or gaining increased appreciation for which tools in fact were used together. This statement does reflect, however, some of the functional assumptions identified above. This functional view was criticized by Michael Schiffer $(1972,1974,1976)$ for its formational naïveté. While Binford (1981a) has denied that his early work can be so characterized - that it did not operate from the "Pompeii premise" - that of other early practitioners of the New Archeology can be, and this perspective is evident in the earliest literature on quantitative archaeological spatial analysis (Gamble, 1991, p. 18) (see Table I).

The variables focused on in these analyses - artifact types and botanical remains or faunal elements by genus or species - are likewise consistent with the goal of identifying tool kits and activity areas on a living floor. That is, if artifact clusters are viewed as referring to tool kits left in specific activity areas, then it makes good sense to focus on chipped stone tool types or biological entities (by taxon) to ground functional inferences about the tool kits and activity areas.

Similarly, analytic techniques were designed to determine if clustering was present and, if so, to partition deposits into those clusters of artifacts, which were assumed to be behaviorally significant. Partitions were defined by cluster analysis, nearest neighbor analysis, and the recognition of density peaks (see Table I for other examples). Interpretations of the partitioned assemblages relied on ethnographically derived, but not yet evaluated "common sense" (sensu Binford, 1981a). [As ethnoarchaeological studies were published, this common sense was challenged (Kroll and Price, p. 1991:2; O'Connell, 1995).]

\section{The Formational Challenge and Conceptual Evolution}

As spatial analytic efforts continued during the 1970s, a parallel concern with those processes responsible for the formation of assemblages emerged (Blankholm, 1991; Hodder and Orton, 1976; Kroll and Price, 1991; O'Connell, 
1993). This concern reflected a response to the formational challenge, a challenge posed by archaeologists to themselves as they attempted to push the archaeological record to recover behavioral and processual information, but found themselves without the necessary knowledge and tools. While Schiffer and colleagues (Schiffer, 1972, 1974, 1976; Reid et al., 1975) vociferously gave voice to the formational challenge, the response to it is obvious in the work of many archaeologists at this time. For example, Ammerman and Feldman's (1974) research on differential discard rates with consequences for assemblage composition and Binford's (1973) work on tool curation, discard, and loss were early, pivotal responses to that challenge. Ethnoarchaeological studies of site structure continue to day in response to this same challenge.

Spatial analysts rapidly embraced the formational view of the archaeological record. They detailed all of the many ways in which humans and nonhumans contributed to site structure (e.g., see Speth, and Johnson, 1976; Newell and Dekin, 1978). Nevertheless, their practice of spatial analysis continued to make use of conceptual and operational tools that were consistent with functional assumptions about the archaeological record. That is, they continued to use partitioning techniques and to rely on artifact types as analytic variables. Through time, however, four conceptual shifts, resonating also in the practice of spatial analysis, became evident.

The first such shift concerned the concept of "tool kits, clusters of artifacts and other items which occur together on occupation floors as a consequence of having been used together in certain activities" (Whallon, 1973, p. 266). Tool kits had been formally inferred by Binford and Binford (1966) from the patterned Mousterian assemblages they analyzed. Researchers attempted spatially to isolate tool kits (as defined above) in archaeological sites. With the publication of Ammerman and Feldman's work as well as Binford's early Nunamiut experiences, the spatially operationalized concept of tool kit was recognized as naive (Whallon, 1978). Indeed, after 1984, no researcher has used spatial analysis to seek tool kits (or toolkits or "toolkits," the quotes highlighting their inferential derivation; see Table I).

A second, more complex, shift is evident in the concept of "activity area." Distilling earlier treatments, Carr (1984, p. 114) defined an activity area as "the location at which an activity was performed in a site, during the behavioral past" and "the location where tools or debris indicating past activity aggregate within a site at the time of excavation." Ethnoarchaeological publications by Yellen (1977) and Binford (1978b) elaborated this concept still further. Yellen (1977, pp. 97, 125-131), for example, found little evidence for specific activities tethered to specific site areas (his understanding of "activity area") at the !Kung residential camps he documented. As depicted in his ring model, he did note 
a central community space, surrounded by nuclear family spaces where domestic activities occurred, and special activity spaces associated with shade or with needs for dedicated space on the site periphery. At the Mask Site, a hunting stand visited by an ever-changing task group of Nunamiut males, Binford (1978b, pp. 348-360) found localization in some activities on the periphery of the site. He also noticed that areas that were greatly used had few discarded items, whereas little-used areas often served as discard loci.

Generalizing from these two studies, Simek (1984, pp. 11-17) distinguished two kinds of activity areas: generalized activity areas, associated with hearths and structures and with associated hearth or door dumps having highly diverse assemblages of secondary refuse; and, peripheral to these, specific activity areas with "externally heterogeneous" primary debris. His work, thus, acknowledged the complex nature of spaces previously glossed as "activity areas." The unqualified term "activity area" continues in use today, and only from its context is its meaning sometimes discernible.

A third conceptual shift concerns the demise of the anthropocentric view of site structure formation. While archaeologists (Simek, 1984; Carr, 1984; Whallon, 1984) recognized that artifact-rich deposits might reflect areas where activities had been conducted, they also recognized that such aggregates could be dumps or geological phenomena. Carr's (1984, pp. 114-115) concepts for describing archaeological deposits in terms of deposition sets, redundantly associated tools and debris created by behavioral, geological, biological, or agricultural processes, and depositional areas, areas containing depositional sets, communicated this important distinction. As Carr (1984, p. 115) emphasized, depositional sets do not necessarily reflect activity sets, nor do depositional areas equate with activity areas. Similarly, Simek (1984, p. 339) concluded, "[C]learly, we can no longer approach the archaeological record assuming all spatial distributions will reveal activity areas."

A final, important conceptual refinement occurred in the late 1970s and early 1980s as spatial analysts recognized that time-averaged or palimpsest deposits were possible and likely (e.g., Kroll and Isaac, 1984) (see Table I). [Other archaeologists (e.g., Ascher 1968) had made similar observations earlier.] While admitting this likelihood, archaeologists often continued to frame their analyses in terms of recovering information about quick-time entities, activity areas (and, also, “activity areas"). Christopher Carr's (1984) critical review of spatial analysis can be read as a magnificent attempt to reconcile the emerging sophisticated understanding of site formation processes and palimpsest deposits with 1970s functional goals. Robert Whallon's (1984) unconstrained clustering method, similarly, introduced a method for analyzing archaeological spatial structure in light of formation process knowledge, 
while still preserving the commitment to search for activity areas in archaeological distributions.

With functional goals still before them, most spatial analysts employed artifact types, usually chipped stone tools, as the fundamental analytic variable. Analytic techniques characterized above as partitive continued in use, with the modification that partitions were based not only on spatial proximity (i.e., spatial similarity) but also on assemblage similarity. Given a partitioned assemblage, compositional analysis of each partition assemblage was conducted to ground functional interpretations of the inferred depositional set. In Simek's (1984) case, he concluded with general formational interpretations of depositional sets on the basis of the homogeneity of assemblages (defined by artifact types and faunal elements).

\section{Recent Analyses}

Recent spatial analyses have absorbed at a more fundamental level the implications of the formation process research carried out in the 1970s and 1980s. Evident in the work of Keeley (1991), Stevenson (1991), Lang (1992), Enloe and colleagues (1994), and Petraglia and colleagues (1994) are the more general analytic goals of inferring formation processes, which may or may not include inferring the presence of activity areas. Concordant with these goals, their analyses rely on analytic variables - artifact attribute states or elements - that actualistic research has identified as sensitive to specific formation processes. For example, Keeley (1991) focuses on edge damage and considers the differential deposition of chipped stone with differing edge damage. Lang (1992) analyzes the orientation of long bones, ratios of large to small bone densities, and ratios of chipped stone to bone densities, all designed to evaluate specific formation processes. Artifacts of different sizes are differentially treated by people during site cleanup (see below); Simms and Heath (1990), Stevenson (1991), and Tipps (1993) use artifact size to argue for specific maintenance behaviors.

Analytic methods and techniques also have evolved. Previously, isopleth (or contour) mapping of artifact densities was used to partition the assemblage. Today, isopleth maps are frequently used to depict the distribution or gradient in formationally sensitive indicators such as edge damage or artifact size, which in turn informs on the generating process. [But see Sullivan (1992a) for a continued use of density peaks to partition assemblages.)

A final important trend in recent archaeological spatial analysis is the comparative analysis of site structure. In his 1984 study, Simek analyzed two Aurignacian levels at Le Flagolet I and Magdalenian deposits at Pincevent 
Section 36 by isolating artifact clusters and determining artifact homogeneity by cluster. He found the structure of the two deposits at Le Flagolet to be similar, but different from that at Pincevent, which he attributed to different maintenance practices. This dumping variability he ascribed either to site context (Le Flagolet is a cave deposit, Pincevent is an open air site) or to an increase in social interaction during the Magdalenian time period. Koetje (1987) expanded this analysis to include open air Magdalenian sites from the Isle Valley and, in this initial analysis, found few similarities be tween the two series, perhaps because of their very different spatial con texts.

In an exceptional analysis, Kind (1985) considered 176 assemblages from a variety of Early, Middle, and Upper Paleolithic sites in Africa and Europe. He used artifact frequency, depicted with symbols proportional in size to the relative frequency, to identify depositional sets having various shapes. He further analyzed the chipped stone tool frequencies of these assemblage polygons using multivariate techniques. From his analysis, he identified trends in depositional set shape through time and according to season of occupation.

Using methods described below, I have compared and contrasted the spatial structures of 362 archaeological surface deposits for which the structure could be warranted as owed primarily to cultural (rather than natural) processes (Wandsnider 1989, pp. 312-339). I found that only about $10 \%$ of the structured assemblages resembled ethnographically documented sites and interpreted the remainder, on the basis of spatial structure and content, in terms of different formational and occupational histories. Unfortunately, these surface deposits included few chronological indicators, limiting their utility in approaching an understanding of systemic land use.

More recently others have made similar attempts. Farizy (1994), for 4 Middle Paleolithic sites, and Koetje (1994), for 11 Upper Paleolithic sites, have compared and contrasted the spatial structures reported there. Relying on visual inspection of maps, Farizy finds evidence for the continued use of places through time without apparent site maintenance. Expanding on his 1987 work, Koetje's (1994) analysis depends on spatial analyses all employing the ?-means clustering technique implemented by different authors. Interestingly, he finds three modes of internal structuring, which he argues are owed to (1) the presence of features and architecture, which focus human activities, and (2) the presence of natural constraints.

As emphasized above, comparisons of this sort are critical to learning about the evolution and occurrence of human "site space" behaviors and the systemic way in which humans and archaic humans negotiated their cultural landscape (Simek, 1984; Binford, 1987). The efforts of Simek, Farizy, and Koetje are highly provocative but are impaired, I suggest, by 
the lack of a standard nomenclature for describing spatial structure. Indeed, the $k$-means clustering algorithm, termed by Kintigh and Ammerman (1982) a heuristic technique and used by Simek and in the analyses summarized by Koetje, is explicitly nonstandard, as it depends on the archaeologist to define "good" cluster solutions. Moreover, it can create only circular partitions and suffers from the other deficiencies of partitive methods noted above. Koetje (1994, pp. 161-162) states, however, that this potential for variation in the spatial units of interpretation did not compromise his analysis

\section{Strategy and Tactics for Archaeological Spatial Analysis}

Thus, evident in Table I and Figure 1 for the 1990s are two different strategies for archaeological spatial analysis. The first is similar to the strategy pioneered by Whallon in the early 1970s in that it emphasizes the partitioning of assemblages. Rather than making functional inferences about the partitioned assemblages, however, formational interpretations are offered (e.g., Sullivan, 1992a, Koetje, 1994). Many of the analysts employing a "partition and characterize" strategy rely on the fc-means clustering algorithm even though, as Christopher Carr (personal communication, 1995) observes, other techniques less demanding in their assumptions [e.g., Carr's (1985) suite of polythetic similarity coefficients and OVERCLUS algorithm, Gladfelter and Tiedmann's (1985) contiguity-anomaly method, and Whallon's (1984) unconstrained clustering] have been published. Carr suggests that the accessibility of this technique-it is available in a user-friendly and well-supported form in Keith Kintigh's Tools for Quantitative Archaeology - is responsible.

The second formational-distributional strategy considers the distribution of formationally sensitive attributes corresponding to one or a few known processes. The spatial patterning of the attribute density grounds an interpretation about the generating process (e.g., Enloe et al., 1994). Site formational history, then, is constructed from several individual analyses of this sort (e.g., Petraglia et al., 1994).

Whether one or the other strategy is used may relate to the relative accessibility of analytic tools. It is also likely owed to different conceptualizations of artifact aggregates. Is a collection of artifacts a deposit (sensu Stein, 1987), in which all items share the same depositional history? If yes, then the partitive strategy is obviously more efficient. If, however, each artifact or element has its own formational trajectory (Jones and Beck, 1992; Schiffer, 1987, pp. 13-15; Wandsnider, 1995), then our analyses have to establish the level at which spatially proximate artifacts share formational histories. The important point here 
is that we, the archaeologists, explicitly decide to approach archaeological deposits as either aggregate phenomena or as collections of artifacts and faunal elements with individual histories. The latter approach, I feel, makes fewer assumptions about the formation history of deposits and may thus serve as a default approach when other information is not available.

Importantly, the second strategy also permits a negative, positive, or indeterminant assessment that a particular structuring process operated in the past. Denning hyenas, for example, may create deposits with one kind of spatial patterning in distinctive gnaw marks. Humans engaged in daily processing and consumption may create deposits with a different distinctive distribution of other gnaw marks. Post-abandonment visitation of a location by other gnawing beasts may create a third distinctive spatial configuration. The strategy developed below, which considers the scale and form of spatial patterning in sensitive attributes, permits the assessment as to whether any of these formational agents has been at work.

Implementing this spatial analysis strategy relies on four tactics. Three are already evident in the recent applications of archaeological spatial analyses and their formal statement is offered here. The fourth is designed to evaluate whether a particular process has been at work and to enable comparative analysis of site structure. All of these are undergirded by the emerging consensus that the goal of spatial analysis lies in the inference of deposit formation history, which subsumes the earlier goal of identifying activity area assemblages and identifying site structure.

The first tactic involves explicitly selecting a formationally sensitive analytic variable (Schiffer, 1983; Carr, 1987, pp. 267; Stein, 1987). Until the 1984 publications by Johnson, and by Kroll and Isaac, artifact and tool types and elements identified by species had often served in this capacity (see Table I). Types, however, are composites of attributes, some of which may be formationally sensitive, many of which are not. Because early spatial analyses analyzed items by type, it is not surprising that analysts were frustrated by difficult-to-interpret patterning and few useful results. Ethnoarchaeological research has identified several artifact and deposit attributes that are sensitive to the formation of spatial structure. Among these is artifact and element size (Stevenson, 1991) as well as edge damage on chipped stone artifacts (Keeley, 1991). Lang (1992) has considered long- bone orientation and various artifact and element ratios. The fat content of bones, which influences the differential disposal of bone elements under conditions of anticipated food stress (Binford, 1978a; Graham, et al., 1982) and also their susceptibility to post-abandonment disturbance by canids and hyeanids (Yellen, 1991), is also formationally sensitive. Simek's (1984) use of deposit homogeneity (by artifact and faunal element) is an example of 
a deposit attribute that, he argued, is sensitive to different kinds of dumping behaviors. See Schiffer (1983, 1987, Chap. 10) for a compendium of such attributes and how they are affected by various processes.

The second tactic concerns the use of distributional rather than partitive methods and techniques for analyzing spatial patterning. This tactic recognizes that the operation of processes often times produces distributional gradients rather than discrete homogenous units. The shape and size of the peaks and valleys, and the slope of the gradient all communicate information about formation processes (Schiffer, 1983; Stein, 1987, pp. 373-375). Distributional methods have been experimented with for some time; Graham's (1980) spectral analysis of grave goods and Carr's (1987) use of the Fourier technique are examples. [See also Rogers and Chasko (1979) and Ebert (1992) for the application of similar methods at a regional scale.] More recently, Lang (1992) has used image processing techniques to characterize the distributions of artifacts and bones at Pincevent. None of these particular distributional techniques has been widely used, perhaps because they are conceptually and technically difficult; the wide availability of low cost image processing software, however, may lead to their increased use (see Lang, 1992).

In the 1970s and early 1980s, isopleth (or contour) mapping of artifact densities often served as a prelude to partitioning the assemblage. More recently, it has been used as another, perhaps more accessible, means for depicting spatial distribution. Binford's (1987) mapping of factor scores, Enloe and colleagues' (1994) mapping of element densities, and the map ping of artifact size or microrefuse densities (O'Connell, 1987; Simms and Heath, 1990; Metcalfe and Heath, 1990; Tipps, 1993) are all recent examples. It is important to note, however, that while contour mapping is an extremely useful exploratory devise, it does not lend itself to consistent application or interpretation (Spear 1979). The descriptive techniques introduced below attempt to deal with these shortcomings.

The third tactic integrates the first two. It suggests focusing on a series of formationally sensitive attributes in turn, describing their distributions, and comparing these with distributions that have been documented actualistically or are theoretically understood. [Rick's (1976) evaluation of slope deposits at the Peruvian cave of Ccurimachay for evidence of gravitational sorting and Fuchs and co-workers' (1977) analysis of Levant Epi-Paleolithic distributions for evidence of eolian sorting processes are examples of the latter.] Depending on the fit between observed and expected distributions, an inference about whether a specific process indeed operated is possible. This series of analyses, then, serves as the basis for constructing a narrative of site formational history. Enloe and colleague's (1994) analysis of Pincevent and Petraglia and 
colleague's (1994) analysis of Abri Defaur reflect this strategy. This tactic is in contrast to earlier strategies that at tempted to identify mostly homogenous depositional sets, presumably with similar depositional histories.

The fourth tactic speaks especially to the issue of comparative archaeological spatial analysis. Equally important, it allows comparison between archaeological and actualistic contexts, thereby permitting an assessment of whether a particular process has been at work. It attempts to provide a means for characterizing and also comparing, for example, isopleth features in terms of their size, shape and gradient. Two things are required: analytic units of uniform size and structural descriptors that describe the articulation of those analytic units. That is, analogous to structural analysis of language, both words and a means for describing the arrangement of those words are required.

For both of these, standard spatial analytic units and structural descriptors, I have drafted the concept of primitive structural element from digital image processing (Gonzalez and Wintz, 1987, p. 430). Primitive (meaning fundamental) structural elements are spatial units of small (relative to the space over which a process operates) and uniform size (derived below) with values describing a single formationally sensitive attribute. "Primitive structural elements" seem superficially similar to map grid cells, which have been commonly employed by archaeologists to depict the distribution of variable values. By using an image processing term, "primitive structural element," rather than the more familiar "grid cell," I hope to convey the potential for image processing concepts to assist in describing archaeological spatial structure. Second, I wish to emphasize that structural elements are analytic rather than behavioral or archaeological units; we specifically design them to meet our analytic goals, in this case, to see structure.

Structural descriptors are indices that describe the relationships between the primitive structural elements. For example, such descriptors can distinguish the different textures or arrangements of black and white pixels evident in images of different basket weavings (Gonzalez and Wintz, 1987, p. 415). Ethnoarchaeological work demonstrates that there is redundancy in how locations are used and how site contents are patterned. Well designed structural descriptors should also be able both to capture and to distinguish among these patterns.

\footnotetext{
* For the dimensionally adventurous, an array of several, independent, formationally sensitive indicators could be associated with each structural element For example, each structural element could have values corresponding to a potential fat index, a homogeneity index, an edge-damage index, and so forth. To keep the discussion simple, I limit the discussion here to the consideration of one formational variable and the values it takes in an image of structural elements.
} 
In the following section, I focus on implementing the fourth tactic, describing archaeological spatial structure, which depends on selecting formationally sensitive attributes and considering their distribution (the first and second tactics). Here I develop and apply several structural descriptors that allow the discrimination and comparison of spatial structure at five ethnoarchaeologically documented sites.

\section{Describing Archaeological Spatial Structure}

In the following, I focus on just one structuring process, site maintenance behavior. After reviewing theory that describes how and why this process works, I consider a variable to measure its operation, the degree to which assemblages are size-sorted. At five ethnoarchaeological sites, the relationship between maintenance behaviors and the spatial structure of size-sorted assemblages is considered. Structural descriptors are designed and used to describe and compare the structure in size-sorting evident at these sites.

\section{Site Maintenance Behaviors}

Site maintenance is one structuring process that has been repeatedly reported upon in ethnoarchaeological studies. Importantly, these studies also note that artifacts with varying qualities and site spaces (also with varying qualities) are differentially maintained. Artifact size appears to be especially (although, situationally) sensitive to site maintenance. The following sections discuss the relationship between maintenance behaviors, which occur in the systemic domain, and size-sorted assemblages, which are found in the archaeological domain.

\section{A Theory of Site Maintenance and the Formation of Size Sorted Deposits}

The work of various researchers demonstrates that artifacts of different sizes have, under certain conditions, characteristically different depositional histories. These depositional trajectories are so different that subsite assemblages with markedly different size profiles will develop. Schiffer (1976, pp. 31, 188; 1983, pp. 679-680; 1987, pp. 62-64; 1988, pp. 472) has widely publicized this phenomenon, reported by one of his students in the early 1970s, as the McKellar Principle, where small items often occur as residual primary refuse and 
large items as secondary refuse. Culturally derived size-sorted assemblages have since been reported in a variety of ethnoarchaeological contexts (Binford, 1978b; DeBoer and Lathrap, 1979; Deal, 1985; Simms, 1988; Stevenson, 1982).

The reasons behind the development of site structure in general and sizesorted assemblages in particular are several. Researchers (Binford, 1978b, 1987; Schiffer, 1987, pp. 58-72; Kneebone, 1990, pp. 47-52) agree that, ultimately, the nature and intensity of place use drive the development of site structure. Theories of site structure development have been proposed by Michael Schiffer and Ronald Kneebone. Each has two components, the first relating to debris generation, and the second to whether the debris is left at the point of production, transported, or destroyed. Binford's ideas on residential sites and their archaeological recognition are also pertinent here.

Schiffer's Waste Stream Theory. Michael Schiffer $(1983,1987)$ has devoted a considerable portion of his career towards understanding the formation of site structure. His work emphasizes waste stream processes, a family of processes that govern the flow of debris from its point of origin to its resting place. The length and configuration of the waste stream, Schiffer argues, is determined by two things, debris generation, related to population size and occupation intensity, and the minimization of debris transport costs. Occupation intensity (Schiffer, 1976, p. 31, 1987, p. 59) is based on the frequency with which a space is used, the variety of activities that occur in that space, and the amount of debris generated as a result of those activities (Schiffer 1987, p. 65). See also Binford (1978b) and Anderson (1982) for a discussion of activity redundancy, frequency, duration, and debris-generating capacity and how these relate to activity intensity.

The other critical determinant is the energy cost of removing debris and the benefits to reducing hindrances and risks to occupants (see Hayden and Cannon, 1983). Maintenance and the degree to which the McKellar Principle operates reflect a least effort, cost-benefit analysis of available options, such as moving to a new location, cleaning a debris-filled location, or conducting the activity in spite of hindrances posed by the debris.

Schiffer's contribution to our understanding the formation of site structure lies in his articulation of useful concepts, such as waste-stream flow, and in his systematic cataloging of processes and their effects. He (e.g., Schiffer, 1987; Seymour and Schiffer, 1987) has used this knowledge to guide the formal analysis of archaeological assemblages. His work has paid less explicit attention to the spatial analysis of these assemblages.

Kneebone's Nonequilibrium Thermodynamic Theory. Recently, Ronald Kneebone (1990) has recast Schiffer's waste-stream theory in terms of the costbenefit of structured activity space. His work draws from nonequilibrium 
thermodynamics and explores ideas on entropy alluded to by Binford (1978b, pp. 354, 359-360, 1987). Importantly, Kneebone's work explains why maintenance and structure is cost-effective and it offers a means to measure the spatial "structuredness" of archaeological sites.

Where Schiffer relied on occupation intensity and least effort calculations, Kneebone refers to energy density and entropy minimization. As Kneebone (1990, pp. 17-44) notes, the Second Law of Thermodynamics states that as energy flows through a system, disorder (measured by entropy or randomness) is produced. With energy flow through structured systems, however, the amount of generated disorder is less, given the same amount of energy flow. Moreover, when the flow of energy increases, open or living systems (e.g., organisms) are able to alter their structures so that the amount of disorder produced is below the maximum increase possible without an altered structure, a finding summarized as the principle of minimum entropy production (Prigogine, 1980; Brooks and Wiley, 1988). Thus, in systems with structure, compared to those without, higher energy flow rates can be sustained. And, as energy levels fluctuate, we see systemic reorganization with a corresponding reduction in disorder. Measures familiar from information theory are used to describe the amount of disorder (or, conversely, the amount of structure).

Kneebone (1990, pp. 46-47) considers people in their activity space as an open or living system. He uses the term energy density, a more general measure that collapses Schiffer's population density and occupation intensity, to describe the total amount of energy expended in an activity space. Holding activity space constant, as population size or the energy generated through various activities increases, then energy density also increases. And as the energy density increases, entropy would also increase were it not for the development of structure.

As energy density increases, Kneebone's model (1990, p. 50) anticipates, first, a formalization and specialization of activity areas, followed by an increase in maintenance behaviors, followed by an investment in permanent facilities, which in turn become increasingly specialized and fixed in space. When this happens, following Kneebone, we can say that there has been a "development of structure" and that the site space has become "more structured."

Kneebone (1990, pp. 45-73) evaluated the efficacy of his thermodynamic model by examining the theoretical relationship for 71 houselots that had been ethnoarchaeologically documented by others in the Tuxtlas mountains (southern Veracruz) and the Puuc area (Yucatan) of Mexico. To measure the structure of the houselots, he calculated maximum entropy, the maximum number of possible system states (e.g., the total number of dumps vs. maintained spaces vs. shelters); coarse entropy, an estimate of actual system 
entropy based on the proportional area in different system states (e.g., the percentage area of individual dumps, maintained spaces, shelters); and redundancy, the difference between maximum entropy and coarse entropy standardized by the maximum entropy (for derivation see Kneebone, 1990, pp. 57-59). High values indicate higher amounts of disorder, i.e., more randomness; lower values indicate more structure. Energy density was approximated by houselot population density.

Considering only the location of dumps on houselots, he reported statistically significant but weak, negative relationships between measures of entropy and energy density. Regressing maximum entropy on population density yielded $r=-0.47(P=0.00004)$; for coarse entropy, $r=-0.43(P=0.0002)$; and for redundancy, $r=-0.35(P=0.003)$. That is, as population density increased, entropy in general decreased (structure increased). He attributed the low regression values to the fact that different kinds of dumps, e.g., with dangerous items, with provisionally discarded items, and so forth, may exist. Also, the unfolding or historical nature of site structure undoubtedly plays an important role in constraining its state at the time of observation. The houselots had been mapped for other purposes and Kneebone had no information on kinds of dumps or on the different kinds of activities conducted at these sites.

When many different kinds of activity space (shelter, maintained, dump, special activity area, and undedicated) were considered, a more complex relationship was seen. In general, maximum entropy was again negatively correlated with population density. The relationship between coarse entropy and redundancy, and population density, however, was very sensitive to the amount of undedicated space. When site space was completely dedicated to some kind of use, the use of that area was observed to be more generalized (high redundancy values). Conversely, with increasing amounts of undedicated space, more specialized space use (lower redundancy values) was seen. And, paradoxically, when very large amounts of undedicated space were available, again, space use was unspecialized.

Kneebone's theory is useful because it explicitly relates a systemic entity, energy density, to an archaeological phenomenon, site structure. Second, it provides measures that allow one to characterize the total amount of structure at an archaeological site. Third, it provides a context for integrating the many ethnoarchaeological observations that have been made on occupation intensity and energy density. These studies include those that focus on aspects of occupation intensity, including population size and makeup (Hitchcock, 1982), occupation duration (Simms, 1989), and the space needs of seasonal activities in seasonal environments (O'Connell, 1987; Simms, 1989). Other research has considered the other aspect of the energy density calculation, constraint in site space. For example, research has been conducted 
on the physical constraints imposed by the natural configuration of the site space (Wandsnider, 1996), including the location of shade (Yellen, 1977; Bartram et al., 1991; Binford, 1987), overhangs offering protection from precipitation, and boulders to protect from cold winds. And, the spatial constraints have also been considered, including those imposed by the strength and repair of social relationships (Binford, 1991; Gargett and Hayden, 1991; Whitelaw, 1991), seasonal labor needs (Binford, 1991), sharing large packages of food (O'Connell, 1987, pp. 99-104; O'Connell et al., 1991; Binford, 1987, 1991), rare community events that may require special facilities (Hitchcock, 1987; Kent, 1991, 1992), events that prompt households to move their position because of death, disagreements, or misunderstandings (Binford, 1991; Fisher and Strickland, 1989, pp. 479-480; O'Connell, 1987, p. 88).

In terms of interpreting hunter-gatherer site structure, Kneebone's implementation is not directly applicable. The measures he uses depend on the accurate identification of shelter, storage, dump, maintained, and other kinds of space. Kneebone was working with archaeological sites interpreted as residences of agriculturalists, and so the presence of features grounds many of these space inferences. With hunter-gatherer sites, such features are fewer or are more ambiguous, making functional identifications of space problematic. For this reason, formationally sensitive artifact attributes are considered here.

One Energy Density-Structure Relationship? Binford's Analysis of Residential Sites. Lewis Binford (1978b, 1983, 1987, 1991) also has directed much research effort to understanding site structure and what it can tell us about the past. Whereas Schiffer and Kneebone focus on occupation intensity and energy density, Binford calls attention to the labor and social organizational aspects of behaviors transacted at locations and how this organization constrains both the initial site structure and ongoing maintenance activities. Cooking, eating, sleeping, and working, when carried by a family unit, generate a waste stream configured differently from that produced by a same sex, adult task group. Moreover, as different kinds of cooperation or labor and food sharing occur, structural variation in residential sites is evident (see also Whitelaw, 1991). Binford's work also emphasizes the relationship between planning depth and the degree to which activity spaces may be maintained; i.e., those areas for which future activities are planned may be maintained, while other such spaces may not.

Residential sites, thus, are locations where high occupation intensities and energy densities are expected to occur and it is here, especially in the domestic area, that maintenance behaviors result in structured (sensu Kneebone, 1990) deposits. Of course, intensely used locations for which future use is expected, like the Mask Site, are also heavily maintained, How structured 
deposits allow us to differentiate between locations used for residential and nonresidential reasons is the crux of much of Binford's site structure work. He suggests that by looking at the character of deposits - their contents, shape, and size - at the core and on the periphery of an occupied area, these organizational distinctions might be possible (Binford, 1978b, 1987).

Kneebone understandably looked for a single relationship between energy density and structure; Binford's work (see also Hodder, 1987; Schiffer, 1988) emphasizes that we should expect a family of such relationships. As the organization of occupant labor (as well as other factors mentioned be low) changes, different relationships between energy density and structured deposits are expected.

In other words, as very rapidly appreciated by early workers in quantitative spatial analysis, the theoretical relationship between maintenance behaviors and site structure is complex, with many contributing parameters.

Dimensions of Energy Density, Dimensions of Site Structure. Kneebone's work looked at the relationship between overall energy density and site structure as a whole. Binford's work suggests that this relationship has several possible states, which depend on labor and social organization. Still other ethnoarchaeological research suggests that specific dimensions of site structure may independently respond to specific dimensions of energy density, as discussed below for size-sorted assemblages.

Stevenson (1991, pp. 270-276) summarizes how size-differentiated deposits develop. He distinguishes between intentional sorting processes and unintentional sorting owed to scuffage, trampling, and children's play. Most important for the purposes of this paper, intentionally sorted deposits form through (1) the simple clearing of a work space (Stevenson, 1985), (2) preventive maintenance described by Binford's (1978b) drop zone/toss zone model, and (3) systematic refuse disposal (Schiffer, 1987; Stevenson, 1991). Expedient clearing seems to occur with occupations that are expected and realized to be short-term. In contrast, preventative toss-and-drop maintenance may occur more often at locations where occupations are brief but reoccupation is expected, as at the Mask site (Binford, 1978b, 1983). For sedentary and semisedentary peoples with a long-term commitment to specific locations, Murray (1980) reports that scheduled refuse disposal is frequently practiced. This practice is illustrated in Simms' (1988) report of a Bedouin camp, O'Connell's (1987, pp. 81-82) report of an Alyawara camp, Deal's (1985) report on a Mayan village, a Mackenzie Basin Dene village described by Janes (1983, pp. 3031), and agricultural households documented by Killion (1992). [See Schiffer (1987), pp. 64-69) for other examples.] 

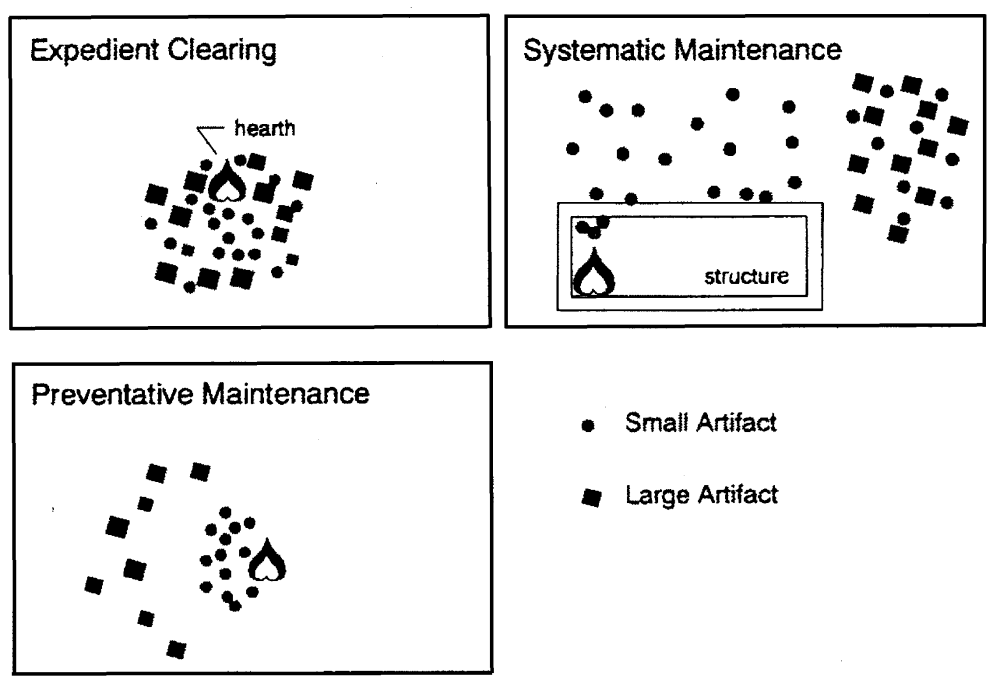

- Small Artifact

Large Artifact

Figure 2. Model of size-differentiated assemblages.

Figure 2 models some of the salient dimensions of site structure, i.e., the differences in the spatial scale, size differentiation, and shape of areas with distinctive refuse for each of these disposal situations. Where expedient clearing of a tenting or work space occurs, a "displacement zone" (Stevenson 1985) with a ring of large items encircling the cleared area develops (see also Binford, 1978b, p. 347). The size of the cleared space reflects the size of the maximum work space needed for one or several contemporaneous tasks, which in turn, will relate to numbers of laborers, numbers of activities, and the space needs of activities. Upon abandonment, however, debris of any size may be left in the work space, speculates Stevenson (1991). Specialized use areas may have size profiles similar to that described here.

In situations where preventative maintenance holds, globular areas of small dropped items are expected. These may be feature focused and are also tethered to a diffuse crescent of large items (Binford, 1978b, 1983). The size of the maintained area relates, again, to the numbers of individuals present and the nature of their activities. Depending on the pitching ability of the occupants, there may be some amount of artifact-free space between the drop zone of residual primary debris and the toss zone of secondary refuse. The size of the dump may relate to the amount of debris generated as well as the total amount time spent at that particular location.

Systemic maintenance involves scheduled sweeping and possibly also transport or burning of debris. It usually occurs at places with features designed for the long term, such as houses, kitchens, and corrals. The shape 
and size of maintained spaces and dumps and their relative distance is different from the first two maintenance scenarios. Now the maintained space is more rectangular or polygonal in shape since it abuts other rectangular facilities. The size of the maintained spaces again relates to numbers of laborers and to the space needs of both common and, importantly, rare activities. The dump or dumps containing sweepings of small and large items as well as kitchen refuse are usually situated off to one or more sides. O'Connell's (1987) description of an Alyawara encampment and Simms' (1988) account of a Bedouin camp illustrate the latter. [Again, see Schiffer (1987) for other examples.] No matter the situation, the maintained areas with mostly small items are often associated with facilities such as hearths and shelter.

In the above, I have highlighted the sizes and shapes of artifact distributions associated with different maintenance and disposal scenarios and having different size profiles. Some of the different dimensions of energy density that differentially influence maintenance were also detailed. Revisiting Yellen's (1977) attempt to infer these systemic qualities of place use from the structure of deposits, the following section considers the construction of structural descriptors sensitive to these aspects of size-sorted assemblages.

\section{Recognizing Size-Sorted Assemblages}

The positioning and size of unmaintained spaces, maintained spaces, and dumps - one currency for describing the structure of a site-are maintenance responses to anticipated and realized energy densities at a location. Moreover, these spaces have both distinctive size and shapes as well as artifact sets with distinctive size profiles. How do we put this information to work?

In the following, I select the scale for the primitive structural elements and develop a size-sorting index (SSI) to describe the relative amounts of small and large items by structural element. ${ }^{*}$ For illustrative purposes, this analysis protocol is applied to familiar ethnoarchaeological examples from Yellen (1977), Binford (1978b), and O'Connell (1987). The selected sites and statistics that describe various dimensions of occupation history are summarized in Table II.

\footnotetext{
* For the purposes of this demonstration, an exact threshold figure is not used. Stevenson (1991, p. 274) reviews literature that suggests that this size threshold may lie between 2 and $9 \mathrm{~cm}$. It will likely be context specific.
} 


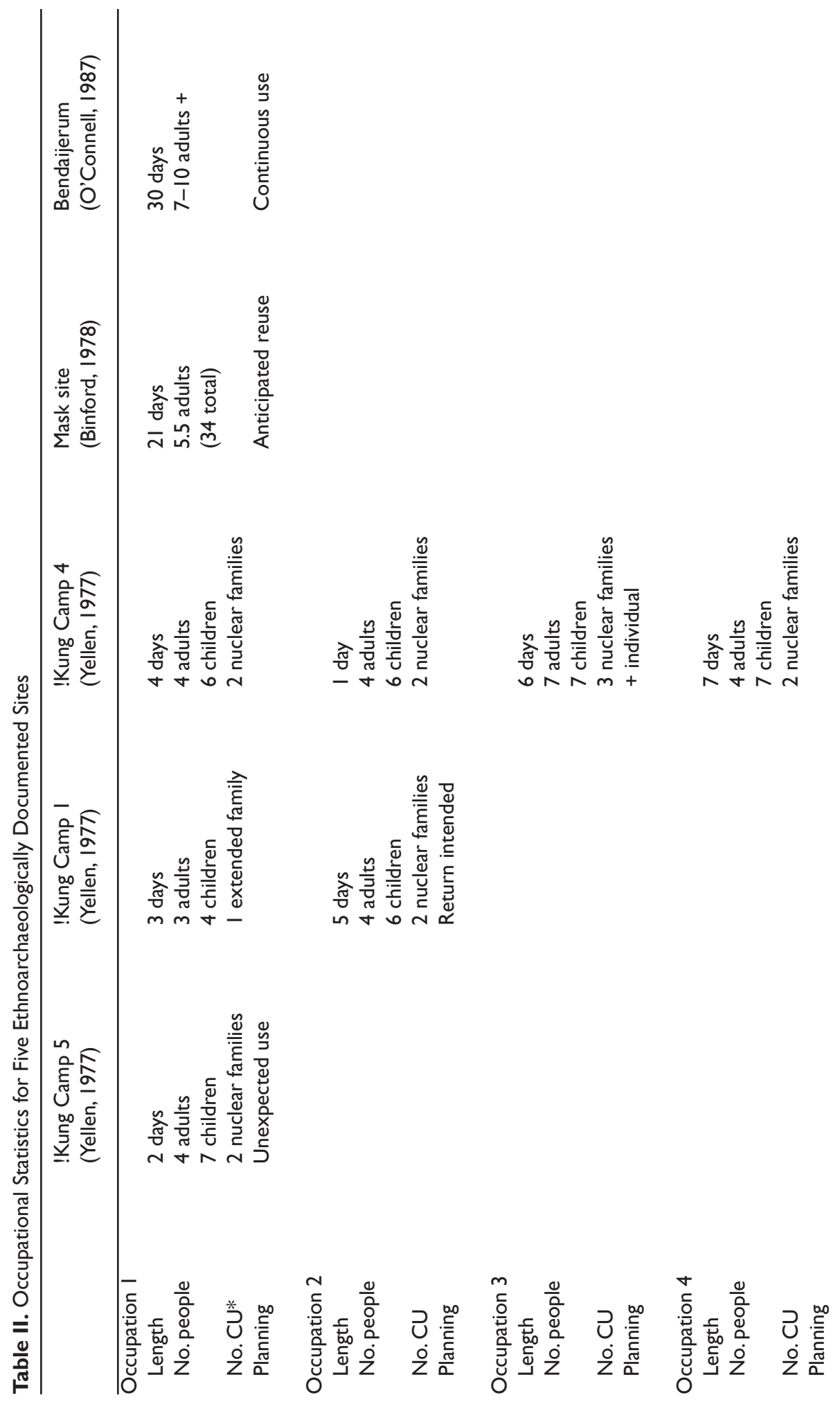




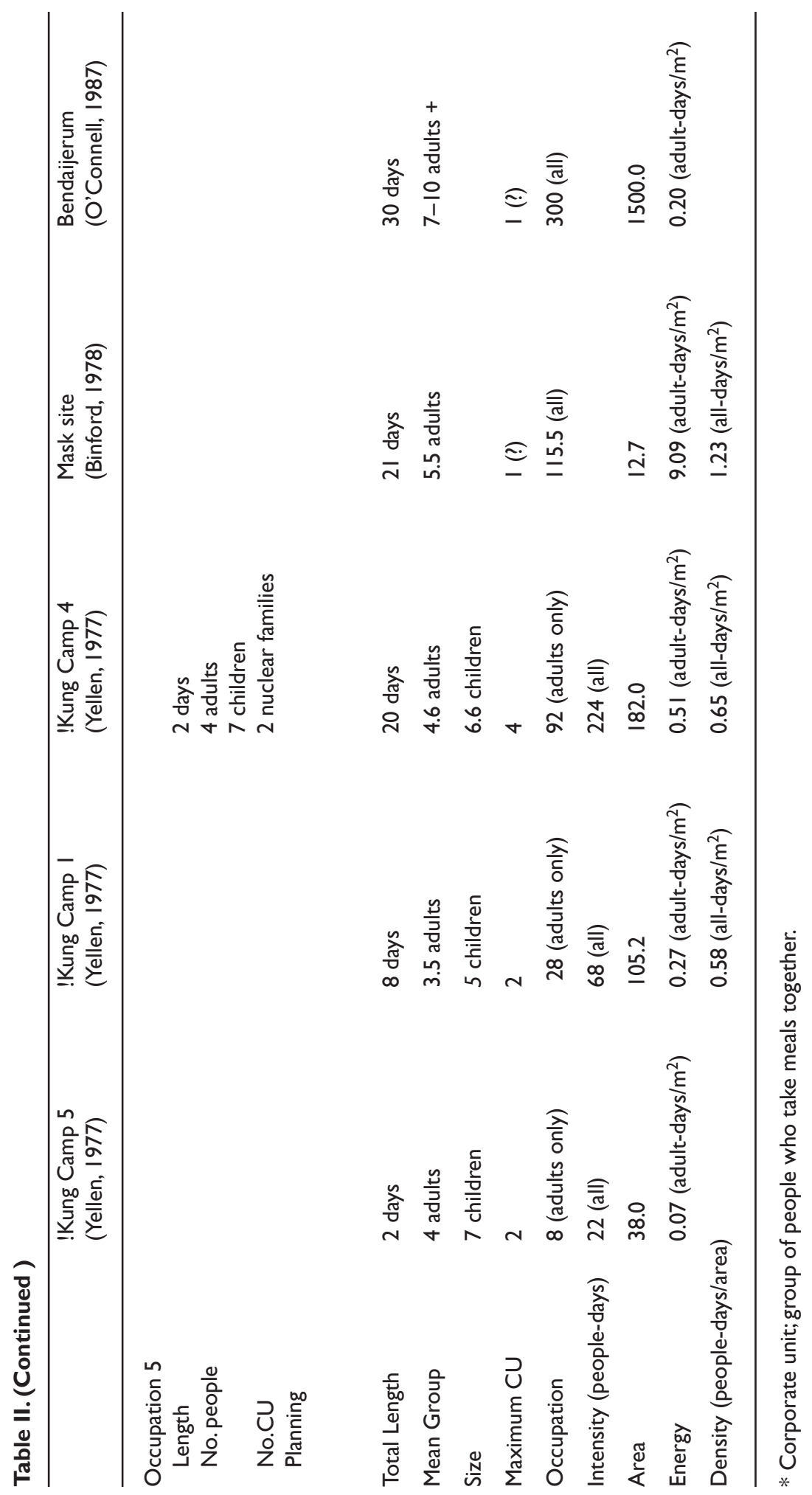




\section{Ethnoarchaeological Data Sets}

Sixteen wet-season camps occupied by several !Kung San families in the Central Kalahari Desert were mapped and reported in detail by John Yellen (1977). Three of the 16 camps were selected: Camp 5, which was occupied briefly by two families and then abandoned; Camp 4, which was occupied by two or three families for a total of 20 days on five separate occasions; and Camp 1, which was occupied on at least two occasions by two families plus additional family members and was scheduled to be revisited to retrieve cached items. Yellen (1977) provides no specific information on item size for the camps he mapped, but he does give descriptions of species, element, and state of faunal remains. From the descriptions of nonperishable and artifactual material, size types of small, large, and indeterminate were generated. (Nut shells, bean pods, sisal grass strands, and other vegetable material were not considered.) To make size assignments, for example, complete giraffe skulls were tallied as large, while a fragment of a giraffe cranium was considered to be of indeterminate size.

The Mask site was used by 34 men over the space of 21 days while waiting for the spring migration of caribou. Various "waiting" activities, including craftwork, snacking, and card-playing were conducted in a central communal area. Other specialized activities carried out on the site periphery included sleeping and target practice. In his description of the Mask site, Binford (1978b) includes maps and size information for some artifact types. Included in this analysis were shell casings, wood shavings, and bone fragments, all considered small, and large bone fragments, which were considered large. Discarded artifacts were not included, since information on size was not available.

A small household was established near Bendaijerum (O'Connell, 1987) by several men in anticipation of a circumcision ceremony for which a large or dance ground (apulla) was required (O'Connell, personal communication, 1995). At the time it was mapped, it had been occupied for about a month. O'Connell (1987) provides relative size and locational information for some artifact types. In this illustration, the arrangements of soft drink cans and pull tabs (1987, p. 96, Figure 13) and of razor blades and tobacco tabs (1987, p. 97, Figure 14) are used. The soft drink cans are considered large, while the soft drink pull tabs, razor blades, and tobacco tabs are regarded as considered small.

In considering these data, I am deliberately ignoring other important processes that are responsible for the spatial character of these assemblages. For example, it is likely that disposal behavior varied between sites because of their ecological setting. In the Kalahari, hyenas and even ungulates provide maid service, consuming bone abandoned by humans and others (Yellen, 
1991, p. 155). At the same time, the substrates at Bendaijerum and the !Kung camps are very loose and sandy, so that these sites are essentially self-maintaining, with small items being absorbed through scuffage (Gifford-Gonzalez et al., 1985; Stockton, 1973; Yellen, 1991, p. 179). The more indurated surface at the Mask site must be actively maintained for it to remain obstacle-free. And, the time passing between deposition and recording is in the case of the Mask site measured in hours and days, for the Bendaijerum household in weeks, and for the !Kung camps in days, weeks, and months. Thus, the postdepositional modification of these assemblages by subsequent visitors is better controlled for some camps than for others.

One last comment is pertinent. Of these five sites, observations on actual maintenance behaviors are available only for the Mask site. The analysis below suggests that maintenance processes as presently understood (see above) were nevertheless clearly operating in the !Kung camps and at the Bendaijerum apulla household.

\section{Structural Element Size}

Structural elements were defined above as fundamental units of spatial analysis. Selection of the scale or size of these structural elements is critical. For example, an advanced very high-resolution radiometer (AVHRR) image, with a pixel size of $1 \mathrm{~km}$, of a city would appear as a mass of blurs; individual structures would be indistinguishable. On a panchromatic SPOT image, with a pixel size of $10 \mathrm{~m}$, however, individual roads and buildings could be discerned. If we are interested in distinguishing individual buildings, then the SPOT image with its smaller pixel size would be appropriate. If, on the other hand, we are interested only in recognizing "city" and "non-city" portions of the image, the larger pixel size would suffice. Similarly, the size of the primitive structural elements is decided on the basis of the scale of the smallest anticipated spatial pattern.

This relationship is known as the Whittaker-Shannon sampling theorem and states that to differentiate a phenomenon with minimum dimension a, a structural element half the size of a must be used (see Hodder and Orton, 1976, pp. 30-37; Rogers, 1982; Carr, 1987, p. 267; Gonzalez and Wintz, 1987, p. 94; Lang, 1992, p. 17). Since it is not just the minimum dimension of the total phenomenon that communicates information, but also its components, even smaller structural elements would be required. Rogers (1982) has demonstrated through simulation that to capture $80 \%$ of the variation in an archaeological spatial phenomenon with a minimum dimension of a, a structural element size of $0.25 \times \alpha$ is required. The seated worker model detailed by Binford (1978b, Figure 4, 1983) (see Table III), with both the feature-associated 
Table III. Activity Area Models from Binford (1983)

\begin{tabular}{lccc}
\hline Model & $\begin{array}{c}\text { Dimensions } \\
(\mathrm{m})\end{array}$ & $\begin{array}{c}\text { Figure } \\
\text { No.(s) }\end{array}$ & $\begin{array}{c}\text { Page } \\
\text { No.(s) }\end{array}$ \\
\hline Single seated worker with hearth & 2 & $82,83,84$ & $149-150$ \\
Multiple seated workers with hearth & $6-7$ & $86,88-90$ & $151-154$ \\
Family hut and hearth & $3-6$ & 114,115 & $174-175$ \\
Standing workers with hearth (e.g., roasting pit) & 6 & 105 & 167 \\
Standing workers, no hearth (e.g., caribou butchering) & 7 & 109 & 170 \\
Sleeping areas, multiple sleepers & $2 \times 6-10$ & 96,97 & $160-161$ \\
\hline
\end{tabular}

drop zone and the crescent-shaped toss zone produced by five seated workers, has total dimensions of about $5 \times 6 \mathrm{~m}$. A structural element of $2.5 \mathrm{~m}(0.50$ $\times 5 \mathrm{~m}$ ) would be minimally necessary to detect the seated worker model; a 1.25 -m structural element $(0.25 \times 5 \mathrm{~m})$ would permit greater definition. In Yellen's (1977) ring model, individual nuclear areas (LNA) with hearths and huts have maximum dimensions that range from 2.2 to $8.2 \mathrm{~m}$. To recognize a sheltered nuclear work area in the structured distribution of artifacts, a 1.1-m (i.e., $0.5 \times 2.2 \mathrm{~m}$ ) structural element dimension is minimally required; a 0.55 $\mathrm{m}$ (i.e., $0.25 \times 2.2 \mathrm{~m}$ ) structural element would permit greater resolution.

!Kung camps are composed of the nuclear spaces as well as communal spaces and peripheral, special activity spaces; their maximum dimensions range from 7.0 to $29.4 \mathrm{~m}$, with a mean of $17.6 \mathrm{~m}$. To detect the smallest ring configuration, a structural element with a dimension of $3.5 \mathrm{~m}$ (i.e., $0.5 \times 7.0$ $\mathrm{m}$ ) would be necessary; $1.75 \mathrm{~m}$ (i.e., $0.25 \times 7.0 \mathrm{~m}$ ) would capture more of the important variation. [See O'Connell $(1987,1995)$ for other comments on the issue of scale.]

Another concern in selecting the structural element size is data density. The data points available from published ethnoarchaeological accounts are, relative to many archaeological situations, of low density. To register any variation in artifact density or in size profiles across the site, a compromise value for the structural element scale of $2.0 \mathrm{~m}$ was therefore selected. A structural element $2.0 \mathrm{~m}$ on a side should allow the resolution of most of the spatial variation in distributions patterned at a scale of $4 \mathrm{~m}$ or more; more detail in the spatial variation of larger scale patternings would also be evident.

\section{Size-Sorting Index}

A size-sorting index describes the size profile of an assemblage. For each structural element, a size-sorting index (SSI) was calculated to indicate the 
degree to which only small, only large, or a mixture of small and large artifacts was found. Highly negative SSI values indicate that all artifacts are large, while highly positive SSI values indicate all small artifacts; SSI values around 0.0 indicate a mixture of artifact sizes. The benefit of the size-sorting index over other summary measures, for example, small-artifact densities (used by Metcalfe and Heath, 1990; Simms and Heath, 1990), is its ability to portray assemblages that have developed as a result of both cleaning and dumping behaviors. Another summary measure, mean artifact size (see O'Connell, 1987), would be determined mostly by the characteristically large number of small artifacts; large artifacts, which typically are quite rare, would exert little influence on the summary measure.

In his image processing analysis of Pincevent, Lang (1992, pp. 45-49) constructed a large-to-small bone index by subtracting the number of small bones from the number of large bones for each structural element. A similar approach is taken here, but first, I standardize the structural element frequencies of small and large items for each site. To calculate the SSI, counts of small and large items were determined for each element. Second, the mean and standard deviation in size class frequencies by element were determined for each site. Third, for each size class, the artifact counts were standardized to a mean of zero and a standard deviation of one, i.e., frequency z-scores were calculated. Finally, for every element, this z-score of large item frequency was subtracted from the z-score of small item frequency. If unstandardized counts had been used rather than z-scores, the size-sorting index would show little variation since the number of small items is generally so much larger than the number of large items. Figure 3 illustrates the calculation of the size-sorting index for Mask site structural elements.

For the sites considered here, the size-sorting indices range from -4.2 to 3.00 with a mean of 0.0 for the Mask site and for Bendaijerum. For the !Kung camps, a range of -1.5 to 1.5 was found.

In Figure 4, the raster images (or choropleth maps) of the SSI values are given for each of the five ethnoarchaeological sites. Note that by using choropleth rather than isopleth maps, the structural elements for which no artifacts or faunal elements were reported also contribute information. The nature of this information is examined in the next section.

\section{Interpreting Size-Sorted Assemblages}

The SSI maps highlight several aspects of the structure of the sites considered here. First, the Mask site is the most compact, i.e., without interior empty structural elements, which may reflect its history of anticipated and 
Small Artifacts

\begin{tabular}{|c|c|c|c|c|c|c|}
\hline 0 & 0 & 0 & 0 & 0 & 0 & 0 \\
\hline 0 & 2 & 10 & 0 & 0 & 0 & 0 \\
\hline 0 & 0 & 25 & 4 & 1 & 0 & 0 \\
\hline 10 & 27 & 45 & 0 & 31 & 0 & 0 \\
\hline 7 & 00 & 4 & 33 & 14 & 0 & 0 \\
\hline 0 & 1 & 0 & 0 & 0 & 0 & 0 \\
\hline
\end{tabular}

Large Artifacts

\begin{tabular}{|c|c|c|c|c|c|c|}
\hline 0 & 0 & 0 & 0 & 0 & 0 & 0 \\
\hline 0 & 3 & 2 & 0 & 0 & 0 & 0 \\
\hline 0 & 14 & 3 & 0 & 0 & 0 & 0 \\
\hline 0 & 2 & 0 & 1 & 2 & 0 & 0 \\
\hline 0 & 0 & 0 & 0 & 1 & 0 & 0 \\
\hline 0 & 0 & 0 & 0 & 0 & 0 & 0 \\
\hline
\end{tabular}

a. Raw Counts
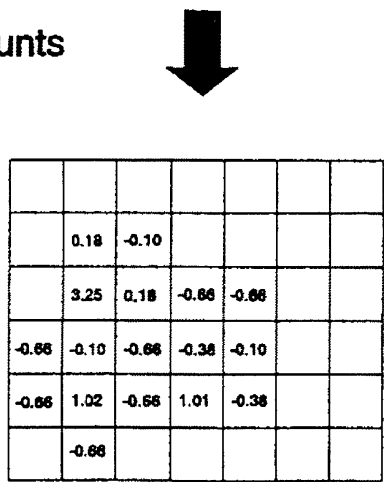

\section{b. Standardized Counts}

Figure 3. Calculation of the SSI values for the Mask site: (a) raw counts; (b) standardized counts; ... (continued)

realized reoccupation for a specialized purpose by small groups of males. Conversely, the !Kung camps and Bendaijerum appear more diffuse. That is, empty structural elements are interspersed with structural elements containing large, small, or both kinds of artifacts. Given the generally lower energy densities (lower population, shorter occupation time) and therefore, lower investment in systematic maintenance of the !Kung sites relative to the others, this is to be expected. The apparent diffuseness of Bendaijerum may be owed to low data density, low overall energy density, or the choice of the size of the structural element relative to the scale at which maintenance behaviors operated at this site.

Second, size-sorted assemblages are evident at all the sites but are most prominent at Bendaijerum and, to a lesser extent, at the Mask site. At the !Kung camps, the structural elements appear as shades of gray, indicating 


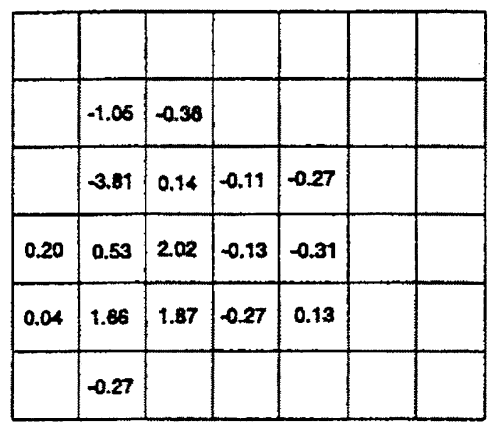

\section{c. SSI: Difference between Small and Large Standardized Counts}

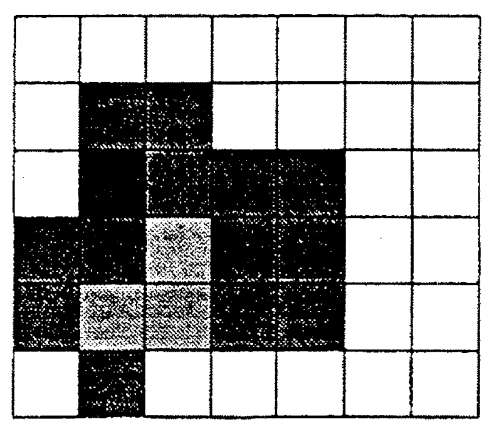

\section{d. Choropleth Map of SSI Values}

Figure 3 (cont.) Calculation of the SSI values for the Mask site: ... (c) SSI values; (d) choropleth (or raster) representation.

that there is not a great deal of variation in the size-sorting index. Apparently, little size-sorting and, therefore, little preventative or systematic maintenance (ala Figure 2) occurred here, at least relative to the other two sites. (The data used in constructing the SSI for the ?Kung camps or post-abandonment homogenization may be responsible for this apparent lack of size-sorting as well.)

At the Mask site and Bendaijerum, more variation is seen. Here, negative SSI values, which indicate the occurrence of large items (usually interpreted 


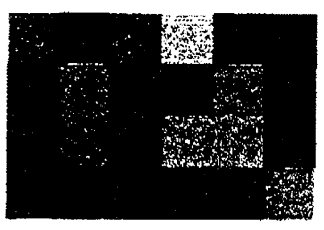

\section{a. IKung Camp 5}

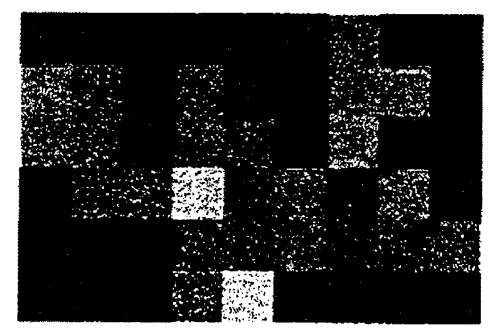

b. !Kung Camp 1

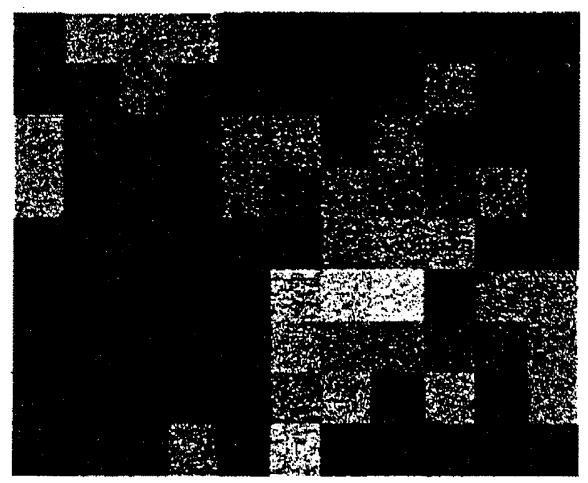

\section{c. !Kung Camp 4}

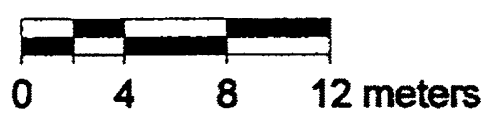

Figure 4. Maps of SSI values for (a) !Kung Camp 5, (b) !Kung Camp 1, (c) !Kung Camp 4, (d) the Mask site, and (e) the Bendaijerum apulla men's household. To display the SSI values as gray values in an 8-bit unsigned raster, the SSI values were transformed using SSI gray value $=($ SSI $\times 20)+156$. This trans formation yielded values of between 50 (dark gray) and 255 (white). Null structural elements, i.e., those without either small or large artifacts, were assigned the gray value of 0 (black). 

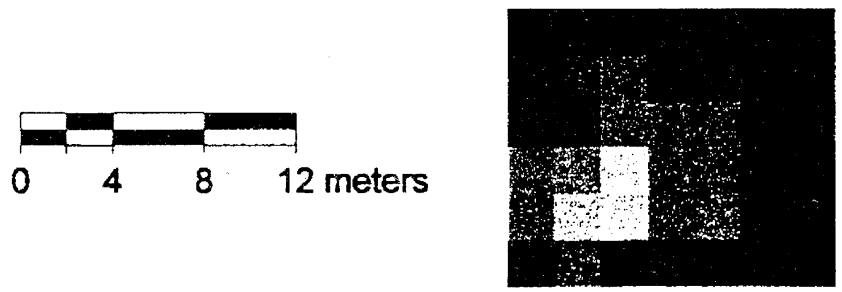

d. Mask Site

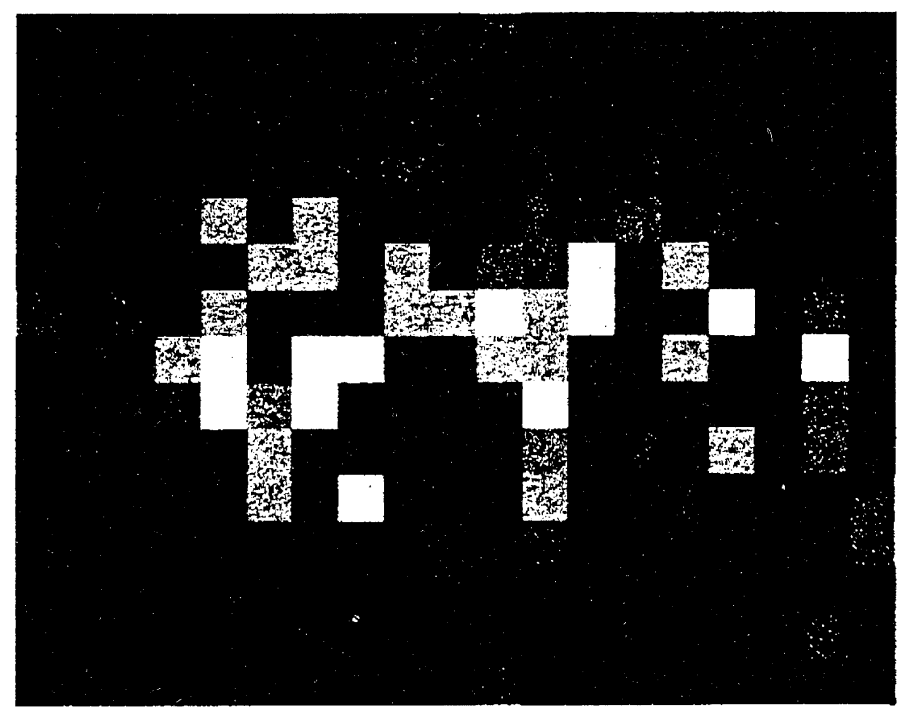

e. Bendaijerum

\section{Structural Elements}
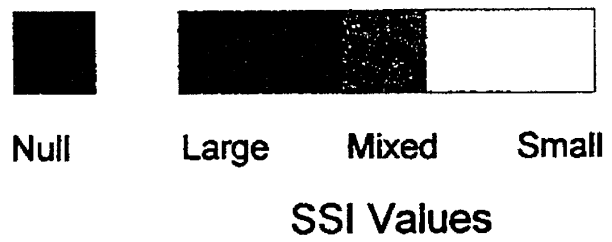

Figure 4 .(cont.)

as "dumps"), occur on the periphery. In the interior are found positive SSI values, indicating concentrations of small items and the lack of large items (usually interpreted as "maintained spaces"). 
Also found on the periphery of these two sites are low absolute SSI values $(-0.75$ to +0.75$)$, where the balance between small and large items is relatively even or where quantities of each are small. This pattern is to be expected at those places where activities generating small and large items are left upon completion of a task and little maintenance follows, such as at specialized activity areas.

Finally, the sizes of the areas with the same difference values differ dramatically between sites. Most dramatic is the large size of the positive SSI area at Bendaijerum This area is congruent with the locations of shade, roasting pits, hearths, and shelters. The next largest continuous area is that seen for the low absolute SSI values at the Mask site. Relatively large expanses of the intermediate SSI elements, indicating unmaintained spaces, are found at the !Kung camps as well.

\section{Structural Descriptors for Describing Archaeological Site Structure}

To this point, statements about site structure have been based on the visual inspection of structural element maps and their size-sorting indices. Structural descriptors, however, can be designed to systematically describe and compare these spatial patterns, both between the ethnographic and the archaeological domains and among archaeological cases, as noted above (Tactic 4). I have developed several such indices to describe the presence of size-sorted assemblages. The indices presented here are based on those that have been developed to perform statistical and structural analysis of image textures [(Gonzalez and Wintz, 1987, pp.414-418); see also the contributions to Simon (1989) and Krzyzak et al. (1989)]. Also relevant are the measures developed by cartographers to describe the complexity of choropleth and isopleth maps (MacEachren, 1982; Monmonier, 1974). In addition to introducing these structural descriptors, I examine their ability to discriminate among the ethnoarchaeological sites and discuss their interpretation in terms of the dimensions of energy density. Here the goal is evaluate the performance of the structural descriptors in light of ethnographic information about the dimensions of occupation (and maintenance behaviors) at these five sites.

\section{Derivation}

Structural descriptors require simplified or "contrasty" images. The digital analysis of image texture, for example, describes the relationships of black and white pixels; in this case, the structure elements have only two values, 


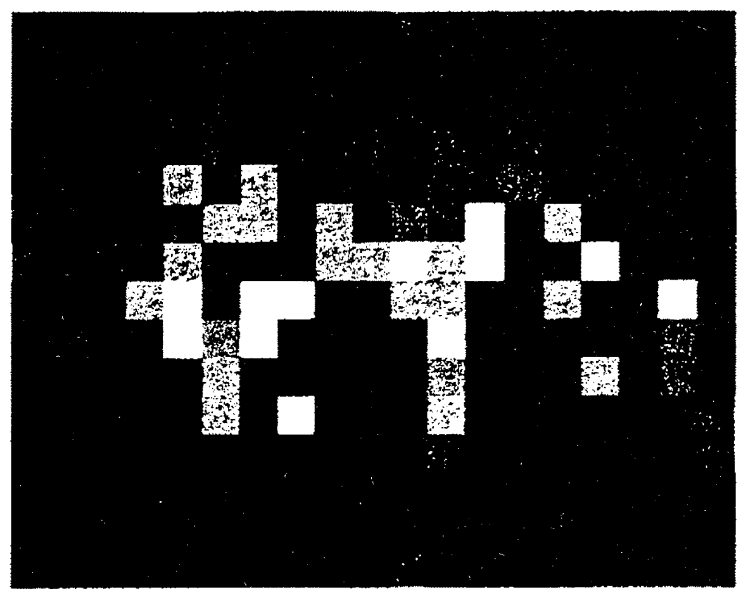

\section{a. Unsimplified \\ (low contrast)}
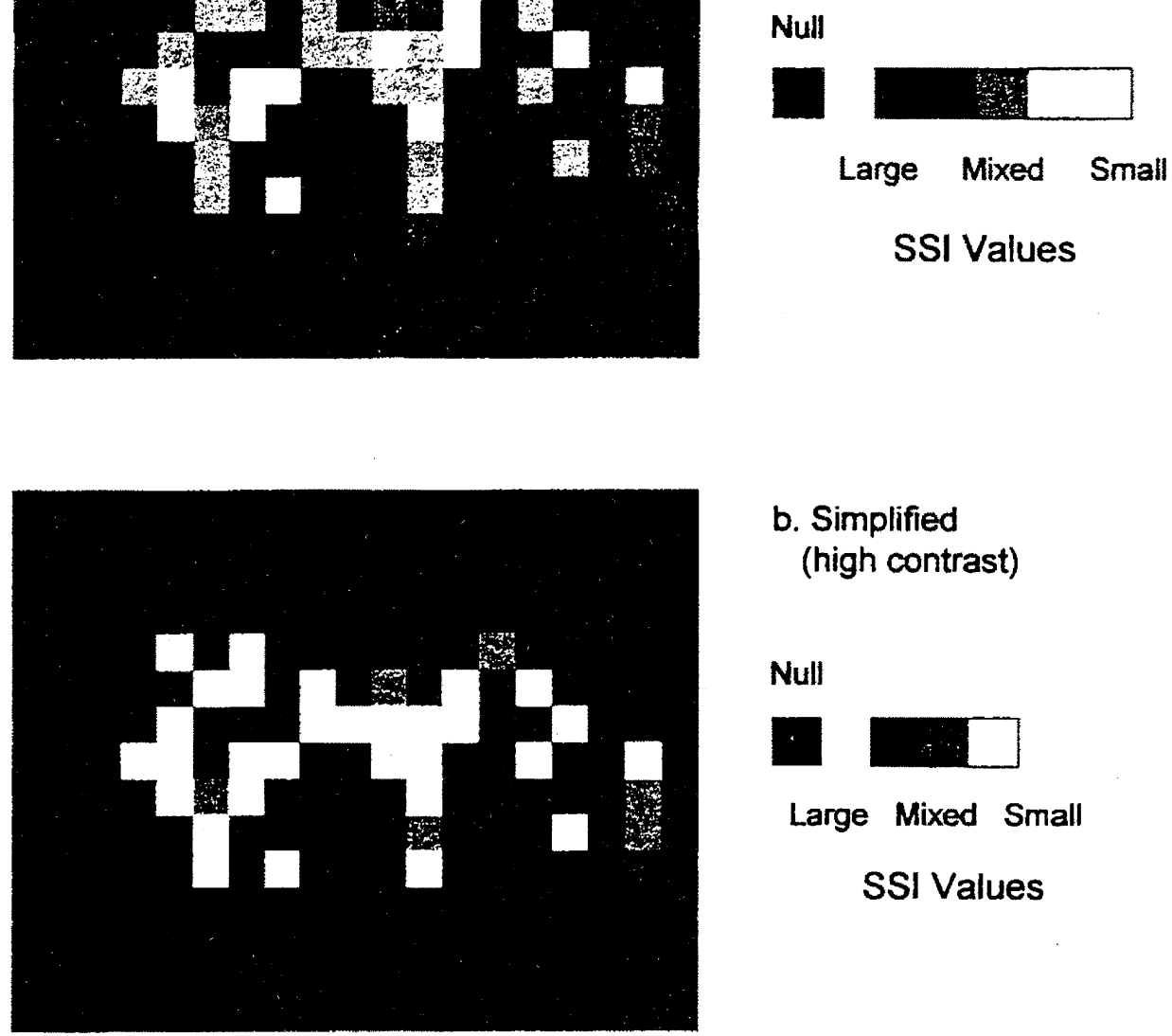

\section{b. Simplified}

(high contrast)

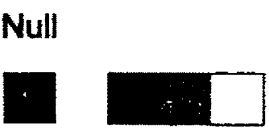

Large Mixed Small

SSI Values

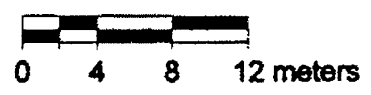

Figure 5. Bendaijerum: (a) an unsimplified (low contrast) image and (b) a simplified (high-contrast) image.

black and white. Here, three arbitrarily defined classes of SSI values are recognized: less than $-0.75,-0.75$ to +0.75 , and greater than 0.75 . In the following discussion I refer to negative, zero, and positive structural elements, which correspond with the preceding SSI value ranges. Thus "negative" structural elements are those dominated by large artifacts, "zero" structural elements refers to the presence of both small and large artifacts, and "positive" structural 


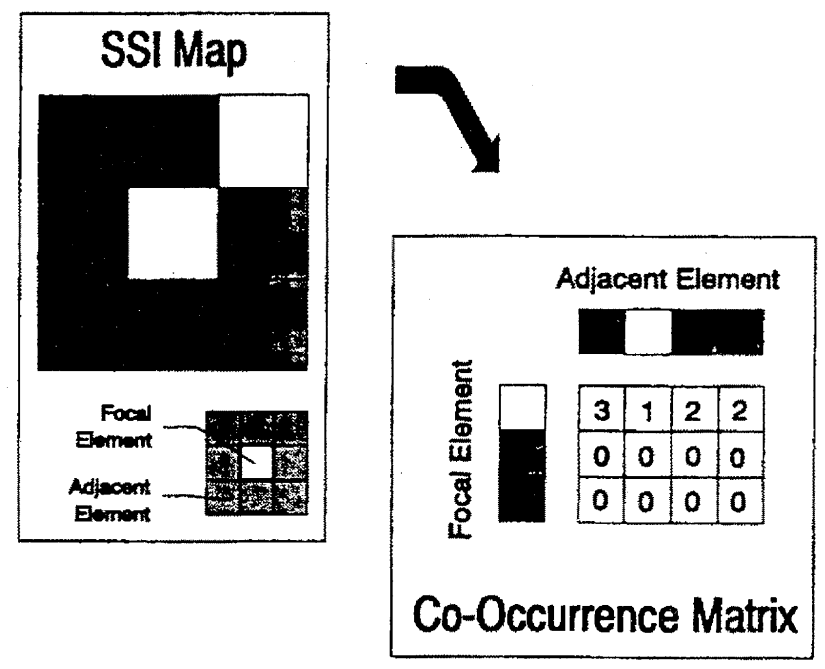

Figure 6. Calculation of a cooccurrence matrix for a focal cell within a hypothetical SSI image. See the Appendix for more information.

elements are those with mostly small artifacts (Figure 5). In addition, "null" structure elements, i.e., those without artifacts and therefore without SSI values, are considered. The structural descriptors presented below describe the salient features of the SSI maps highlighted in the preceding discussion.

The structural descriptors summarize various aspects of the relation ship between a focal element and the eight elements adjoining it. The focal element is an arbitrarily selected structural element that is evaluated in terms of its SSI value class and the SSI classes of adjoining elements (see Figure 6). All structural elements in the site "image" are considered in turn as focal elements. See the Appendix for the derivation of the structural descriptors. ${ }^{*}$

Three flavors of descriptors were developed: aggregate, contiguity, and co-occurrence. The first basic kind, aggregate descriptors, describes the overall arrangement of the elements within the image. The compactness descriptor compares the arrangement of the artifact-bearing elements to all structural elements in the image. It informs on how diffuse or compact the site assemblage appears to be. Sites with no empty structural elements have high compactness values; sites with many empty structural elements have low compactness values. In terms of human behavior, activities that are tethered to point sources such as a hearth or an animal that is being butchered may

\footnotetext{
* The program was written in Turbo Pascal Version 5.0 and is available upon request from the author. It also can be downloaded in uncompiled form from http://www.unl.edu/anthro/Homepage.html
} 
result in very compact distributions of artifacts. Where activities are tethered to moving points or areas, such as shade or the light available at a cave mouth, more diffuse deposits may be created.

The uniformity descriptor is similar to Kneebone's entropy measure. It is a richness index that describes the degree to which interelement relationships are the same or uniform throughout the image. If, for example, a random distribution of elements with different SSI classes occurs, then the number of null elements that abut negative, zero, and positive elements will be approximately the same, as will the number of negative elements that abut zero or positive elements and the number of abutting zero and positive elements. In this case, the distribution is said to be very uniform and a low uniformity value is obtained. When one or two such cooccurrences predominate, a high uniformity value results. Such would be the case if, for example, negative elements adjoined only null and no other class of elements. Low values for uniformity are expected at locations where there is little systematic maintenance and high values in the opposite situation.

The second kind of structural descriptor, contiguity descriptors, characterizes the degree to which elements with similar SSI values are contiguous. Four descriptors are included here. The first three contiguity descriptors are individually calculated for negative, positive, and zero structural elements (termed negative contiguity, positive contiguity, and zero contiguity descriptors, respectively). These indices were designed to inform on the presence and size of depositional sets with similar size profiles. High negative contiguity is expected where dumps are found. High zero contiguity values are expected where primary deposits or special use deposits occur or, for example, where deposits created through sweeping occur. High positive contiguity values are expected for large maintained spaces. The last contiguity descriptor, grain, is calculated from the positive contiguity index and the total number of elements with small artifacts. It thus gives an indication of the maximum size of maintained space at a location.

The third basic kind of structural index, cooccurrence descriptors (also called joint probability values in the following), describes the juxtaposition of structural elements with differing SSI values. Six indices of this kind were developed. The negative-zero cooccurrence descriptor, for example, reports the joint probability that a negative element abuts a zero structural element, while the negative-positive cooccurrence descriptor describes the relative number of times that a negative element and positive element abut. In addition, zero-positive, negative-null, zero-null, and positive-null joint probabilities were all calculated. These indices were designed to help characterize the arrangement of the structural elements. For example, a high negative-null joint 
Table IV. Structural Descriptor Values for Five Ethnoarchaeological Sites

\begin{tabular}{lccccc}
\hline $\begin{array}{l}\text { Index } \\
\text { Camp 5 }\end{array}$ & $\begin{array}{r}\text { !Kung } \\
\text { Camp I }\end{array}$ & $\begin{array}{r}\text { !Kung } \\
\text { Camp 4 }\end{array}$ & $\begin{array}{r}\text { Mask } \\
\text { site }\end{array}$ & $\begin{array}{r}\text { Bendai- } \\
\text { jerum }\end{array}$ \\
\hline $\begin{array}{l}\text { Aggregate descriptors } \\
\text { Compactness }\end{array}$ & 0.61 & 0.78 & 0.66 & 0.98 & 0.46 \\
Uniformity & 0.06 & 0.08 & 0.03 & 0.09 & 0.01 \\
Contiguity descriptors & & & & & \\
Negative & 0.00 & 0.00 & 0.13 & 1.00 & 0.29 \\
Zero & 0.41 & 0.64 & 0.43 & 0.69 & 0.09 \\
Positive & 0.00 & 0.00 & 0.33 & 1.00 & 0.40 \\
Grain & 0.00 & 0.00 & 1.33 & 3.00 & 12.13 \\
Cooccurrence (joint probability) descriptors & & & & \\
Negative-zero & 0.02 & 0.02 & 0.03 & 0.04 & 0.00 \\
Negative-positive & 0.01 & 0.00 & 0.00 & 0.00 & 0.01 \\
Zero-positive & 0.02 & 0.02 & 0.02 & 0.06 & 0.01 \\
Negative-Null & 0.00 & 0.01 & 0.02 & 0.03 & 0.08 \\
Zero-null & 0.23 & 0.19 & 0.15 & 0.18 & 0.01 \\
Positive-null & 0.03 & 0.01 & 0.02 & 0.02 & 0.06 \\
\hline
\end{tabular}

probability indicates that deposits of large items abut empty space, as seen with dumps located on the periphery of some ethnoarchaeologically documented camps. Zero-positive and negative-positive descriptors may have relatively high values if cleared spaces are located at the core of the site.

\section{Structure Discrimination and Systemic Interpretation}

Table IV summarizes the structural descriptors calculated for the five ethnoarchaeological sites. They were designed to capture critical information about the structure in size-sorted assemblages, which form through site maintenance. How well do the descriptors perform? In the interest of space, I focus on seven of the descriptors that seem most useful in describing spatial structure in terms of the operation of size-sorting processes.

Compactness describes the relationship of artifact-free space to artifact space within site space. Visually, the Mask site (Figure 4) appears very compact, with no artifact-free spaces in the site core; conversely, Bendaijerum appears more diffuse, with pockets of empty space occurring within, the site space. The !Kung camps appear intermediate to these two. All of the many factors mentioned above, e.g., the degree to which activities are tethered to point features such as hearths and diffuse features such as shade, are undoubtedly responsible for this variation. Values for compactness clearly 


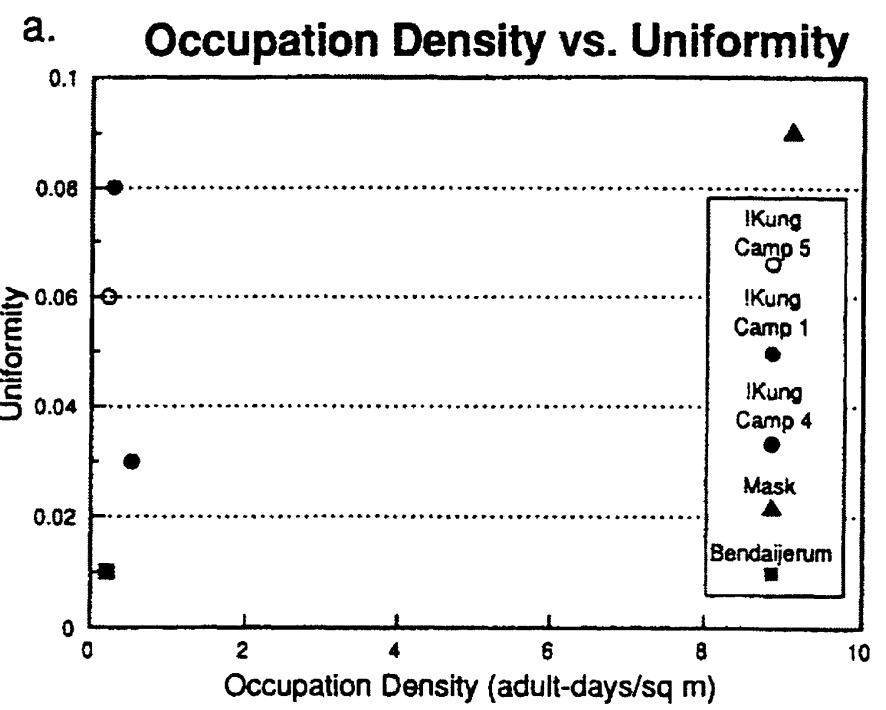

b.

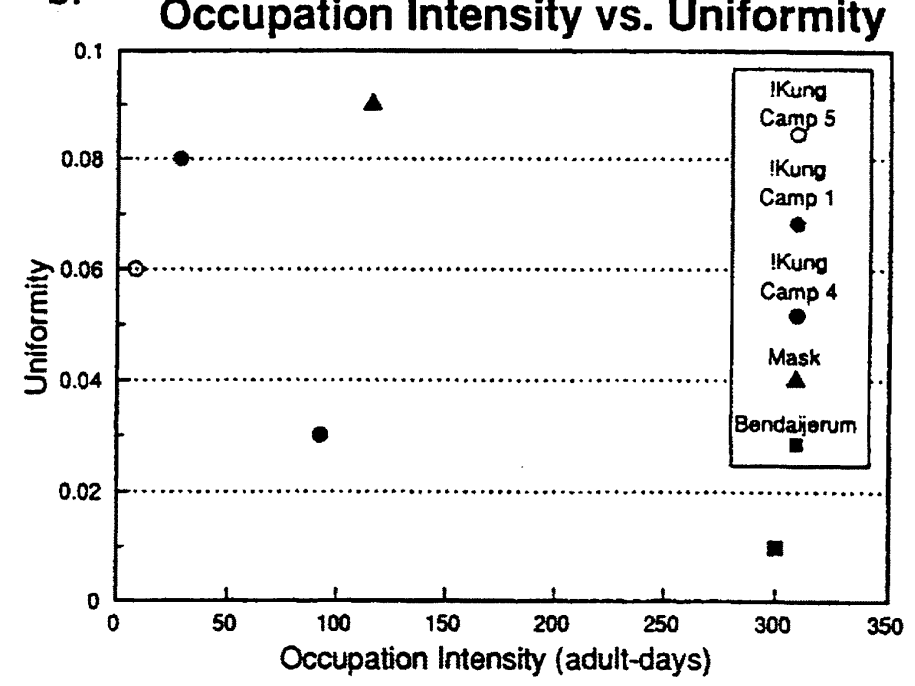

Figure 7. Uniformity versus (a) occupation density and (b) occupation intensity.

differ between the ethnoarchaeological examples, with the Mask site having high compactness values, that for Bendaijerum being low, and the !Kung camps having intermediate values. The compactness descriptor appears to describe well what is visually perceived.

Uniformity is one measure of entropy. In his study of Mayan farmsteads, Kneebone (1990) found a negative relationship between measures of entropy and energy densities, with high entropy values (indicating little structure) 
found at sites with low energy densities, and vice versa. Here, high uniformity values indicate a lack of uniformity and the presence of structure; low values indicate a more uniform distribution of SSI values. Figure 7a shows no relationship between uniformity and energy density. When uniformity and occupation intensity are considered (Figure $7 \mathrm{~b}$ ), how ever, there is the suggestion of a negative relationship, with high uniformity values associated with low occupation intensities and low uniformity values associated with high occupation intensities. Note that this relationship is the inverse of that observed by Kneebone, as high uniformity values describe an uneven distribution of probabilities within the joint probability matrix. Either Kneebone's observations do not generalize to the ethnoarchaeological contexts examined here or the uniformity measure is inappropriate for measuring the presence of structure owed to maintenance behaviors. Because of other findings (see below), I prefer the latter interpretation.

The contiguity descriptors describe the extensiveness of individual deposits of large, mixed, or small artifacts. At the Mask site, for example, all elements containing only large artifacts occur together in the area labeled by Binford (1978b) as the toss zone; hence its high negative contiguity measure. At !Kung Camps 5 and 1, none of the elements with only large artifacts abut; thus, the negative contiguity measures of 0.0 . This lack of designated dumps is expected if little or no systematic maintenance occurred at these locations.

Positive contiguity describes the relative degree to which elements with only small artifacts are contiguous. Where systematic maintenance has occurred and generalized work areas are maintained, relatively large values should be seen. Figure 8 shows there to be a positive relationship between energy density and positive contiguity, with ?he Mask site having both a high energy density and a high positive contiguity. The other sites have relatively low energy densities; intermediate positive contiguity values are seen for Bendaijerum and the !Kung Camp 4 and values of 0.0 for the remaining two !Kung camps. At face value, positive contiguity seems sensitive to aspects of site structure and maintenance behaviors. The number, size, and distribution of corporate work spaces, however, probably influence this measure to an unknown degree.

A related measure is that of grain, which takes into account both positive contiguity and also the number of elements with only small artifacts. Thus, it provides a measure of the size or grain of maintained space. Ethnoarchaeological research suggests that the size of the maintained space is conditioned by work party size and the space demands of concurrent activities. As shown in Figs. 9a and b, values for grain increase as the number of adults at a site increases and also as occupation intensity (i.e., person-days) increases. Grain, 


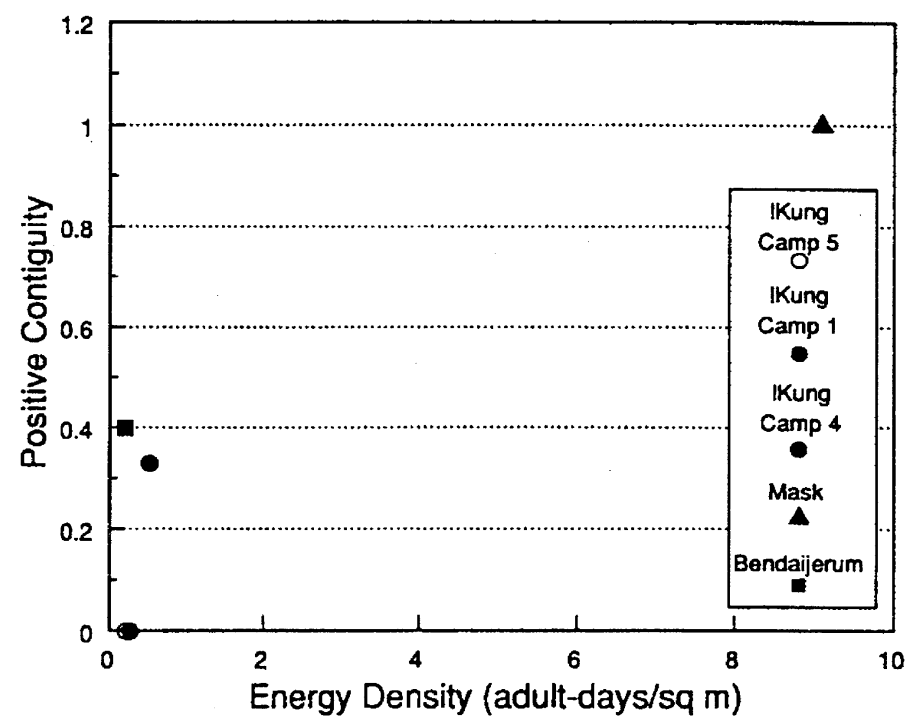

Figure 8. Positive contiguity versus energy density.

thus, appears to be sensitive to the amount of space maintained at particular locations.

Where positive contiguity and grain focus on the cleanup side of maintenance behaviors, the negative-null joint probability describes the presence and location of peripheral dumps (Figure 10). This measure depicts the degree to which elements with large items (i.e., dump deposits) abut elements without artifacts. The high negative-null joint probability values seen for Bendaijerum, where men lived for a month while preparing to host an initiation, and the low values seen at!Kung Camps 1 and 5, which were occupied by a small number of adults and their families for a few days, are therefore expected.

One other measure appears especially sensitive to maintenance activities. The zero-null joint probability covaries in expected ways with the occupation length (Figure 11). At sites occupied for a few days (e.g., !Kung Camps 5 and 1), the relative proportion of zero elements (i.e., those with mixed assemblages) that adjoin empty elements is high; for sites occupied for longer time periods, the opposite is seen. This finding is likely related to the amount and rate of debris generation. That is, during a few days of occupation, relatively little refuse may be generated and may therefore be left in primary context. With longer occupation spans and the accumulation of more debris, systematic maintenance occurs, with the result that size-sorted deposits increase and homogeneous deposits decrease (Simms, 1988). The zero-null joint probability measure appears to be sensitive to this trend. 
a.

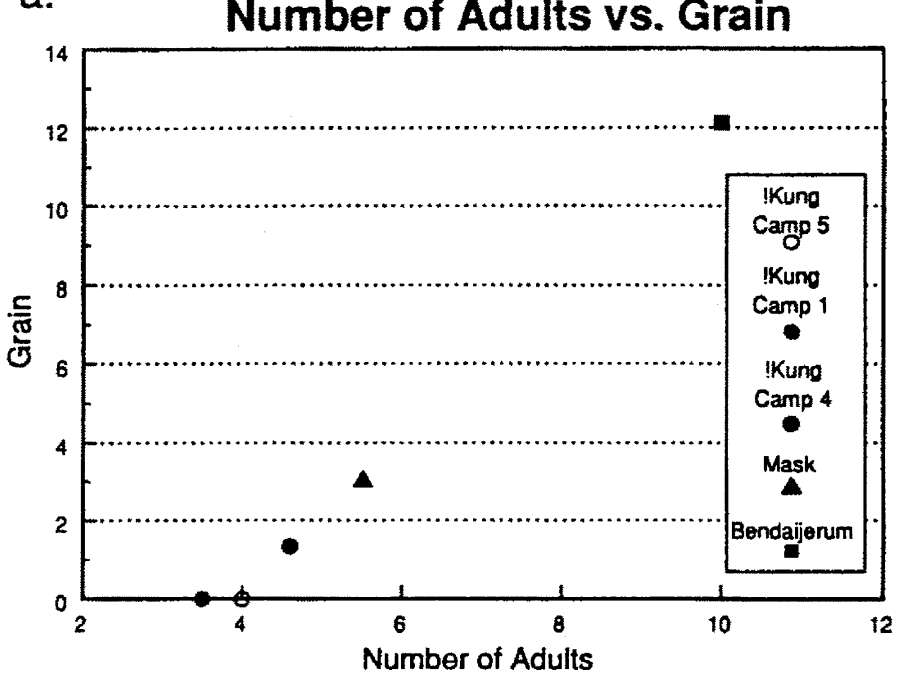

b. Occupation Intensity vs. Grain

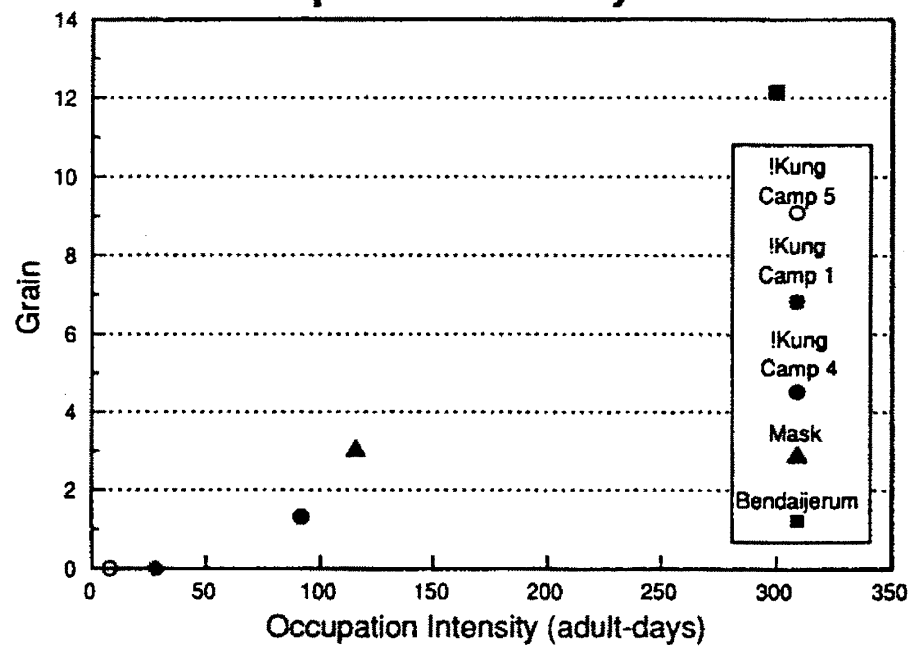

Figure 9. Grain versus (a) number of adults and (b) occupation intensity.

This presentation of descriptor performance suggests (1) that, for the most part, the descriptors are able to discriminate salient features of size sorted assemblages and (2) that patterns in size-sorted assemblages so defined correlate well with our understanding of the formation of such assemblages. An exception to this statement is the uniformity descriptor, which performed exactly opposite to what was expected. 


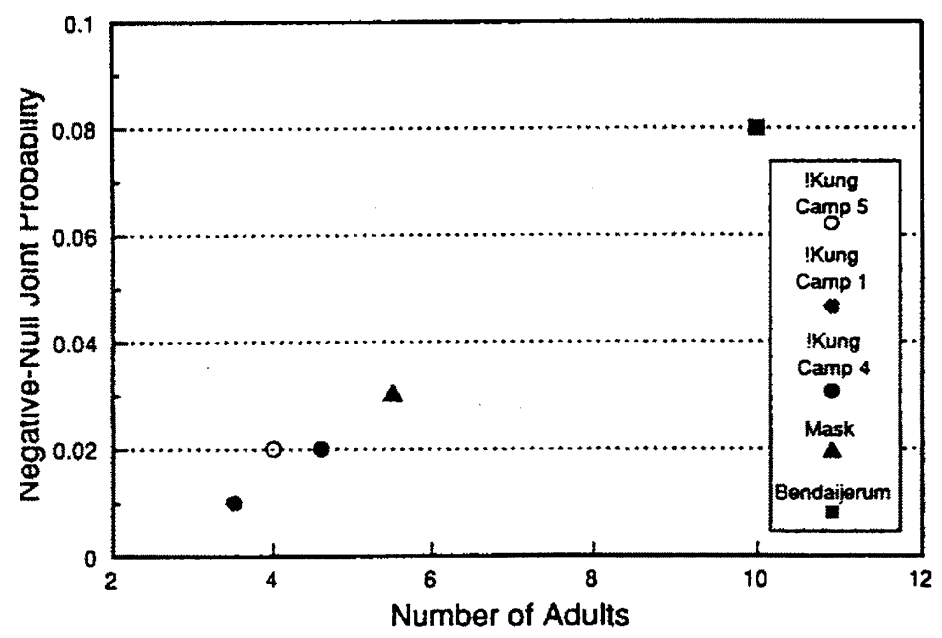

b.

Occupation Intensity vs. Negative-Null Joint Probability

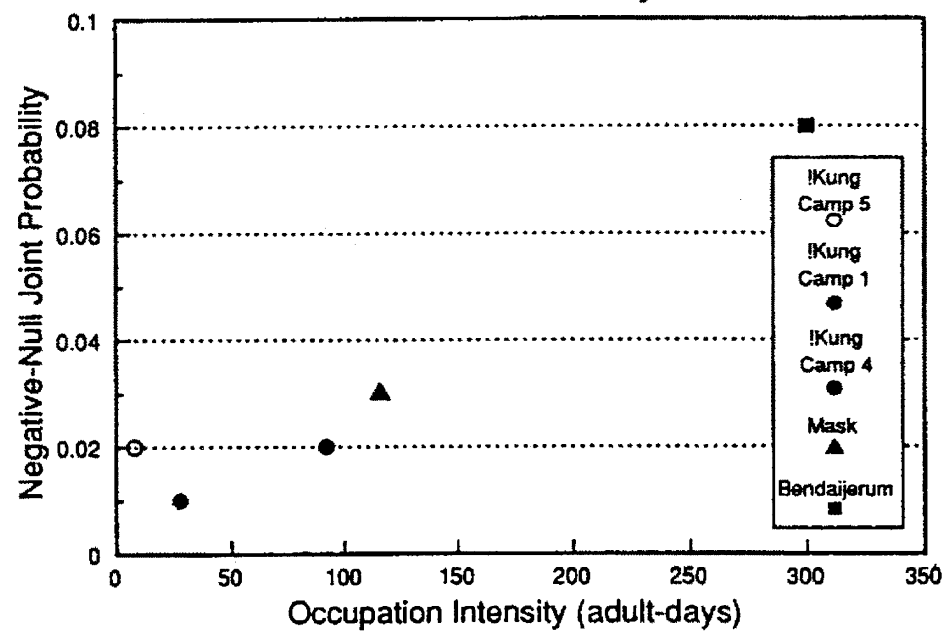

Figure 10. Negative-null joint probability versus (a) number of adults and (b) occupation intensity.

One other point deserves mention. First, the work of Binford and others leads us to expect a family of relationships between maintenance behaviors and spatial patterns. For example, we might expect the spatial patterning seen at the !Kung camps to be different from that produced at the Bendaijerum apulla camp and at the Mask site. At the former, two to four families were in residence and small packages of food were acquired, processed, 


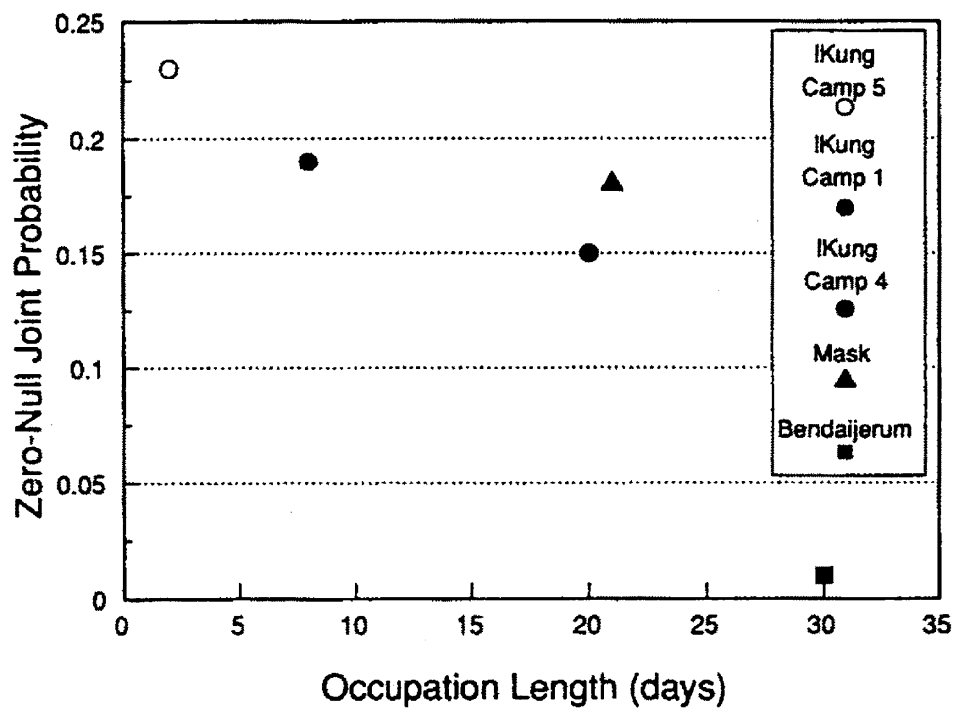

Figure 11. Zero-null joint probability versus occupation length.

and consumed daily by the family units. At the other two sites, only men were present and were organized in a single cooperative unit. At the Mask site, membership of this unit was ever-changing, and at Bendaijerum, it fluctuated to some extent over the span of occupation. At the Mask site, snacking foods that required little additional processing were imported. The activities conducted at Bendaijerum likely were similar to those reported for the !Kung camps, i.e., daily acquisition and processing. For these reasons, the waste streams and the consequent spatial patterns are likely different among the !Kung camps, the Mask site, and Bendaijerum. In the figures presented above, there are too few data points truly to speak to this issue, but it is noteworthy that the !Kung camps usually cluster together and are arrayed in a consistent fashion. Yet some of the figures also suggest the existence of a simple relationship between grain, negative-null cooccurrence, and zero-null cooccurrence, on one hand, and factors conditioning that structure, i.e., occupation intensity, adults present, and occupation length, on the other hand.

In sum, the process of site maintenance is complex in operation and in resulting deposits. This complexity means that, in fact, several different structural descriptors are required to describe the structure of the resulting deposits. The utility of this approach is supported, I think, by these preliminary results. 


\section{Technical Reflections}

The above represents an initial attempt to develop structural descriptors sensitive to those aspects of maintenance behaviors that ethnoarchaeological research has determined to be important. A number of technical issues require attention.

First, the datum points or origins for the SSI choropleth maps were arbitrarily selected; structural elements created from different origins might have produced somewhat different SSI maps. In spatial analysis exercises conducted for Douglas Price in the mid-1970s, students repeated a particular spatial analysis a number of times, each time adjusting the analytic map origin to a new position. A similar practice could be automated and the resulting variation between iterations examined. If much variation is seen, then the size of the structural element may require adjustment. If little variation is seen, then any one result would be as useful as another.

Second, in the above I used a structural element size of $2 \mathrm{~m}$, because of the interest in detecting patterning attributable to seated or standing activities and the density of the available data. Different disposal behaviors and other formation processes, however, operate at different spatial scales and structural element size must be selected accordingly. Lang (1992), for example, used a structural element of $10 \mathrm{~cm}$, which permitted him to resolve detailed patterns in the distribution of bones and chipped stone at Pincevent. In a series of recommendations directed primarily to the CRM community, O'Connell (1993) suggests proveniencing artifacts to the nearest 1-m. While the $1 \mathrm{~m}$ structural element size will capture most variation in structure owed to most maintenance processes, it will not permit an evaluation of the effect of origin selection. For this reason, a $50-\mathrm{cm}$ element size may be advisable when point-proveniencing is not possible. As indicated above, the processes to be researched would dictate the selection of the structural element size. Indeed, it would may also be useful to run this analysis at a series of spatial scales to detect the operation of multiple processes.

Third, the structural indices presented above can determine the size of contiguous areas with all large artifacts, all small artifacts, and artifacts of mixed sizes. They cannot distinguish the shape of those contiguous areas, however. The work of Segen (1989), which focuses on shape indices, should be very useful in this regard.

Fourth, our ethnoarchaeological sample of sites include those covering large areas where several corporate groups operated [e.g., the large site of Bendaijerum $(400 \times 500 \mathrm{~m})$ described by O'Connell (1987); not the small apulla household featured here]. In these cases, it will be useful, in the parlance 
of digital image processing, to segment the distributions of large sites into smaller images, which are then individually analyzed (Gonzalez and Wintz, 1987, pp. 331-388). Such a tactic would be important for large areas with continuous artifact scatters; elsewhere, I have used density criteria to segment the image of the Seedskadee archaeological landscape (Wandsnider, 1989).

Fifth, the descriptors described here and those yet to be developed require calibration with other actualistic data sets to perfect their performance. As recently as 1987, Binford pointed to the dearth of ethnoarchaeological studies reporting on site structure. Today, there are many such studies, from a wide range of geographic and organizational situations (e.g., see Whitelaw, 1991), upon which to draw.

More technically, the sensitivity of these descriptors to images of structural elements that have been filtered, transformed, enhanced, and so forth (Gonzalez and Wintz, 1987, Chap. 4), must also be entertained. Lang's (1992) image processing analysis of various Pincevent "images" is important in this area.

Finally, this discussion has focused on describing the distribution of attributes in two dimensions. As Koetje (1990) notes, however, archaeological deposits are three-dimensional phenomena. Especially in thick deposits, it would be useful to examine and describe attribute data by "voxels" (volumetric elements), rather than pixels (two-dimensional structural elements discussed here). While conceptualizing the image processing tools needed for manipulating voxels is relatively easy, actually programming these tools has proved challenging. This area is the focus of much research in digital image processing and appropriate tools should be available in the next several years (Prabir Bhattacharya, personal communication, 1995). As with the application of digital image processing to two-dimensional archaeological phenomenon, these tools will require some modification to be of use.

In sum, there are several areas that require attention before the comparative structural descriptors proposed here can be widely applied. However, none of these issues, as posed above, appear to be insurmountable.

\section{Discussion and Implications}

In the preceding, I have attempted to illustrate the design and use of structure elements and descriptors to describe spatial patterning in formational terms. Several implications for the interpretation of archaeological spatial structure follow from this attempt, as highlighted here.

First, archaeology is rich in the high-quality spatial information amassed over the last decades; the interpretation of those data, however, 
has been less than satisfying. The gray literature is replete with maps of artifact distributions and density plots, often by material class or chipped stone tool type. Interpretations of these figures, in terms of activity areas, is usually fairly ad hoc and could probably have been generated without the major investment in map production. By explicitly focusing on the distribution of a single attribute known to be formationally sensitive, the potential for extracting useful and unique information about the site, e.g., its occupation intensity or energy density, is very great. And, by describing assemblages in a consistent fashion, with structural descriptors of the kind proposed here, we can begin to more rigorously identify universal and idiosyncratic patterns in the organization of site space, as most recently attempted by Koetje (1994).

A second implication concerns the inferential process. Actualistic research has produced a compendium of knowledge about cultural objects and the processes that act on them. Michael Schiffer (1987) has systematized this knowledge, but the application of it to archaeological situations has been mostly limited to the formal domain. What is needed is a companion volume that describes the spatial patterning associated with particular processes and particular formational attributes. With this in hand, similarities and dissimilarities between archaeologically and actualistically documented site structures, as attempted by Kroll and Isaac (1984) and Kind (1985), could be better assessed. And, with information in this form, it would be a relatively straightforward task to create turn-key "smart" analytic systems that automatically analyze a deposit with respect to a whole suite of formationally sensitive attributes and at variety of spatial scales.

A third implication deals with the time-averaged nature of archaeological deposits. In this exercise, I have deliberately utilized ethnoarchaeological sites with abbreviated use histories to demonstrate the ability of the SSI elements and descriptors to detect culturally important structure. The potential number of formational processes and the sequence in which they have operated at a location, however, are limitless. That is, the potential number of formational histories is infinite. It may therefore be desirable to investigate and spatially analyze contemporary locations that have undergone formation at the boundaries of various specifiable conditions. For example, a series of "Pompeii" assemblages might be examined, as could a series of locations subject to the continuous scavenging discussed by Ascher (1968) for Seri communities. Furthermore, it may be useful to look at how the preceding use of a location conditions its subsequent use. Perhaps a bounded number of formational trajectories can be identified. 


\section{Conclusion}

Archaeological deposits present us with spatially patterned artifacts and features. Linking those spatial patterns to proximate aspects of structure formation and, ultimately, to understanding the past land use system in which evolution and culture change occurred is one goal I see for spatial analysis.

In this regard, I have attempted several things here. First, some archaeologists restrict the analysis of archaeological spatial patterning to the study of "site structure," that is, spatial patterns owed to cultural behaviors at archaeological locations. A reading of the recent literature on quantified spatial analysis, however, suggests that other archaeologists have expanded the purview of archaeological spatial analysis. In some recent analyses, the spatial structure owed to cultural activities is still very much the focus but also entertained are other structuring processes. I have suggested that this expanded purview is necessary for archaeological spatial studies to contribute unique information about the formation history of deposits, which will be especially useful in the comparative study of archaeological places (Binford, 1982; Koetje, 1987; Rossignol and Wandsnider, 1992).

Second, for the spatial analysis of archaeological deposits to produce unique and interesting information about the past that is defensible, I have argued that comparative spatial analysis is critical. Because the theory that relates site maintenance processes and site structure is complex and contains parameters that are archaeologically difficult to control, archaeological identification of maintenance processes, for example, is not possible. For this reason, multiple, incompletely performing indicators of maintenance processes for many deposits that variously share formation histories are required to "tack" to defensible interpretations for individual deposits. Comparative spatial analyses plays an important inferential role in this case.

A third contribution of this paper is that of extending the analytic tactics already in place. Methodologically, an historical review of quantitative spatial analysis shows an emerging congruence between the assumptions about the potential for spatial analysis and its actual practice. Archaeologists today assume that deposits are structured because of the actions of a number of processes, including those considered within the earlier functional approach to site structure studies. Today, the practice of archaeological spatial studies involves (1) paying explicit attention to artifact and element attributes that are known or suspected to be sensitive to specific structuring processes, (2) describing spatial patterns in terms of the distribution of those attributes, and (3) assessing whether particular processes have been at work. Some recent analyses have considered a suite of such indicators (e.g., Enloe et al., 1994; Petraglia et al., 1994) and have constructed formational narratives for the deposits in question. 
To describe archaeological spatial structure in formational terms, I have proposed considering archaeological deposits as images composed of structural elements, i.e., uniform spatial units. The gray values of the elements in the image represent the values of formationally sensitive indicators. To describe the articulation of structural elements with different gray values, structural descriptors are employed. With these descriptive tools, the comparison of spatial patternings among and between deposits, which has been attempted by some (e.g., Simek, 1984; Kind, 1985; Koetje, 1987, 1994; Wandsnider, 1989; Farizy, 1994), can be undertaken with greater rigor and reliability. Through such comparative efforts, the conditional or contextual nature of structuring processes can be better understood, as can the role of places within the regional land use system. The latter observations, in turn, would serve as the data points to be accommodated by larger theories of human behavior, toward which O'Connell (1987, 1995; see also O'Connell et al., 1991), Binford (1987), and others are working.

Finally, I have illustrated the implementation and utility of this last tactic by analyzing five ethnoarchaeologically documented sites. The process of site maintenance, to which artifact size appears to be sensitive, was the formational focus. A size-sorting index was calculated to characterize the size profile of the artifacts contained by each structural element. A series of structural descriptors was designed to describe rapidly and consistently the articulation of structural elements with different SSI values so as to recognize depositional sets that may reflect unmaintained space, maintained space, and dumps. Many, but not all, of the descriptors considered here perform as designed and appear to yield information on spatial structure owed to maintenance processes. Other structural descriptors would need to be developed to detect other spatial patterns produced by other processes.

Robert Whallon and others introduced to archaeology the promise of quantitative archaeological spatial analysis for illuminating the past more than two decades ago. Since that introduction, quantitative archaeological spatial analysis has traveled very far toward realizing that promise, as recently mapped by Blankholm (1991), Gamble (1991), and Kroll and Price (1991). I am hopeful that, in another two decades, this promise will be fulfilled.

Acknowledgments - Michael Johnson assisted in interpreting the data from the ethnoarchaeological site maps, for which I am eternally grateful. Confusion in the use of the term "activity area" was clarified for me during a 
discussion with Jackie Rossignol and Roger Anyon; I thank them for sharing their thoughts. Comments by Peter Bleed, Ralph Hartley, Todd Koetje, Sheena Panja, Steven Simms, and an anonymous reviewer resulted in a much improved paper, and I thank them. I especially wish to acknowledge the help of Christopher Carr, James O'Connell, and Michael Schiffer in making this a better paper. And I also am indebted to Lewis Binford, who created an exciting environment at the University of New Mexico where numerous ideas on site structure and spatial patterning were hatched and debated. I remain responsible for errors in thought and practice.

\section{Appendix A}

Let $\mathbf{A}$ be an image matrix of $x$ structural elements arranged in $k$ rows and $l$ columns, with $1 \leq i \leq k$ and $1 \leq j \leq l$. Each $a_{i j}$ element in A may have $m$ possible SSI classes $z_{1} \ldots z_{m}$. For example, consider a $5 \times 4$ image matrix with four possible SSI classes, $z_{1}=0, z_{2}=1, z_{3}=2$, and $z_{4}=3$ :

$\mathbf{A}=\begin{array}{llll}0 & 0 & 0 & 0 \\ 0 & 1 & 2 & 0 \\ 0 & 1 & 2 & 0 \\ 0 & 3 & 3 & 0 \\ 0 & 0 & 0 & 0\end{array}$

[In the current application, $z=0$ corresponds to empty or null structural elements, $z=1$ refers to negative structural elements (SSI class $<-0.75$ ), $z=2$ to zero elements (SSI class -0.75 to +0.75 ), and $z=3$ to positive elements (SSI class $>+0.75$ ). For consistency in computing the following descriptors, the image matrix contains beginning and ending rows and columns of null values.]

Let $\mathbf{A}^{\prime}$ be a submatrix of $\mathbf{A}$ that includes those elements $a_{i=2 \ldots k-1, j=2 \ldots l-1}$ that may be considered as focal elements. The elements in this submatrix are denoted $a_{i^{\prime} j}{ }^{\prime}$.

Now let $\mathbf{C}$ be an $m \times m$ matrix with elements $c_{u v}$ representing the number of times that the focal element with SSI class $z_{u}$ adjoins an element of another or the same SSI class $z_{v}$. Adjoining elements are those elements lying, with respect to the focal element, immediately above, below, to the left, to the right, or along the four diagonals. $\mathbf{C}$ is defined here (contra Gonzalez and Wintz, 1987, p. 416) as the cooccurrence matrix.

In the above example, consider focal element $a_{2,2}$, which has a SSI class value of $z_{2}=1$. Eight elements always adjoin the focal element. Of these, five 
are SSI classes of 0 , one has a SSI class value of 1 , and another two have values of 2. For this focal element, then,

$\begin{array}{lllll}0 & 0 & 0 & 0 \\ \mathbf{C}_{a 2,2}=\quad & 1 & 2 & 0 \\ & 5 & 0 & 0 & 0 \\ 0 & 0 & 0 & 0\end{array}$

$c_{2,1}=5$ is the number of times that an element with SSI class $z_{1}=0$ adjoins the focal element with SSI class $z_{2}=1$. The number of times that the focal cell and an adjoining element have the same SSI class, $z_{2}=1$, is $c_{2,2}=1$. The focal element adjoins two other elements with SSI classes $z_{3}=2$ yielding $c_{2,3}=2$. No elements with SSI class $z_{4}=3$ abut it, therefore, $c_{2,4}=0$.

In this application, the co-occurrence matrix is accumulated for all focal elements, $a_{i^{\prime} j}{ }^{\prime}$. For this example, the matrix $\mathbf{C}$ corresponding to $\mathbf{A}$ is:

$\mathrm{C} \quad \begin{array}{ccccc}0 & 0 & 0 & 0 \\ 8 & 2 & 4 & 2 \\ 8 & 4 & 2 & 2 \\ 10 & 2 & 2 & 2\end{array}$

$\mathbf{P}$, the joint probability matrix, is derived from $\mathbf{C}$ by dividing each element Cuv by $n$, the maximum possible number of cooccurrences. As noted above, eight cooccurrence evaluations are made for each focal element and each image contains $\left(\begin{array}{l}i \\ 2\end{array}\right) \times(j-2)$ focal elements. Thus,

$$
n=(i-2)(j-2)(8)
$$

and

$$
p_{u v}=c_{u v} / n
$$

In this case, $n=(5-2)(4-2)(8)=48$. Therefore,

$$
\begin{array}{lllll} 
& 0.00 & 0.00 & 0.00 & 0.00 \\
& 0.17 & 0.04 & 0.08 & 0.04 \\
& 0.17 & 0.08 & 0.04 & 0.04 \\
0.21 & 0.04 & 0.04 & 0.04
\end{array}
$$

Finally, let be $\mathbf{F}$ be a $1 \times m$ matrix that contains the total count of focal elements with different SSI classes $z_{m}$. $f_{1}$ refers to the total number of $z_{1}$ (null) focal elements, $f_{2}$ to the total number of $z_{2}$ (negative) elements, and so forth. 
In the example here,

$$
\mathbf{F} \quad=\begin{array}{llll}
0 & 2 & 2 & 2
\end{array}
$$

From these three matrices, $\mathbf{C}, \mathbf{P}$, and $\mathbf{F}$, all of the structural descriptors are calculated. The contiguity structural descriptors involve $c_{2,2^{\prime}} c_{3,3^{\prime}} c_{4,4}$ (i.e., adjoining elements with same SSI classes), while the cooccurrence descriptors focus on the nondiagonal (i.e., adjoining elements with different SSI classes) elements of the joint probability matrix $\mathbf{P}$.

In the following, $\mathrm{K}$ is a function that calculates the maximum contiguity value given $x$ elements. The contiguity value is the number of times that two elements with the same SSI class abut and is computed over all focal elements with the same SSI classes. For example, suppose that an image has two elements with the same SSI class. If the elements do not abut each other, their contiguity value is 0 . If both elements abut each other, the contiguity value is 2 , since the first is contiguous with the second and the second is contiguous with the first. That is, $K(2)=2$. For three elements with the same SSI class, if neither abuts the other, the contiguity value is 0 . If they are arranged in a line, then the contiguity value is 4 . If all are mutually adjoining, the contiguity value is 6 . Thus, $\mathrm{K}(3)=6$. $[\mathrm{K}(1)$ is defined as 0 .]

\section{Aggregate Descriptors}

Aggregate descriptors give summary information about the image as a whole.

Compact is the number of the nonnull cooccurrences divided by the maximum contiguity possible, given the total number of nonnull elements. Images without interior null values will have high compactness values. Images with many interior null elements will have low values. Compact:

$$
\frac{\sum_{u} \sum_{v} c_{u v}}{\mathrm{~K}\left(f_{2}+f_{3}+f_{4}\right)} \quad 2 \leq u \leq 4, \quad 2 \leq v \leq 4
$$

Uniformity describes the evenness or uniformity of $p_{u v}$ values for all nonnull focal elements (Gonzalez and Wintz, 1987, p. 417). Low values indicate that all $p_{u v}$ are about the same, signifying a random distribution of elements with various SSI classes in the image. High values indicate that one or more 
of the $p_{u v}$ values is higher, compared with the others, signifying that there is nonrandom structure present in the image. Uniformity:

$$
\sum_{u} \sum_{v} p_{u v}^{2} \quad 2 \leq u \leq 4, \quad 1 \leq v \leq 4
$$

\section{Contiguity Descriptors}

The contiguity descriptors give information about adjoining elements that happen to have the same SSI classes.

Negative contiguity is the number of observed contiguous negative elements (large artifacts dominate) standardized by the maximum contiguity value, given the actual number of $z_{2}$ elements, $f_{2}$. It may indicate the relative occurrence of dumps. Negative contiguity:

$$
c_{2,2} / \mathrm{K}\left(f_{2}\right)
$$

Zero contiguity is the number of observed contiguous zero elements (small and large artifacts) standardized by the maximum contiguity value, given the actual number of $z_{3}$ elements, $f_{3}$. It may indicate the relative occurrence of primary deposits or pockets of sweepings that include small and large artifacts. Zero contiguity:

$$
c_{3,3} / \mathrm{K}\left(f_{3}\right)
$$

Positive contiguity is the number of observed contiguous positive elements (small artifacts dominate) standardized by the maximum possible contiguity value, given the actual number of $z_{4}$ elements, $f_{4}$. It may indicate the relative occurrence of maintained spaces. Positive contiguity:

$$
c_{4,4} / \mathrm{K}\left(f_{4}\right)
$$

Grain is the product of the number of positive elements and the pro portion of those that are contiguous. Grain should give an absolute indication of the size of the maintained space. Grain:

$$
f_{4}\left(\frac{c_{4,4}}{\mathrm{~K}\left(f_{4}\right)}\right)
$$

\section{Cooccurrence (Joint Probability) Descriptors}

The cooccurrence descriptors focus on the individual joint probabilities in $\mathbf{P}$ and describe the degree to which elements with different SSI classes abut. The negative-null and zero-null descriptors carry the most information in terms of maintenance behavior. 


\begin{tabular}{|c|c|c|}
\hline Negative-zero: & $p_{2,3}$ & \\
\hline Negative-positive: & $p_{2,4}$ & \\
\hline Zero-positive: & $p_{3,4}$ & \\
\hline Negative-null: & $p_{2,1}$ & $\begin{array}{l}\text { [high if dumps (owed to systematic } \\
\text { maintenance) are on image periphery] }\end{array}$ \\
\hline Zero-null: & $p_{3,1}$ & $\begin{array}{l}\text { [high if mixed assemblages (owed to } \\
\text { clearing) are on the image periphery] }\end{array}$ \\
\hline Positive-null: & $p_{4,1}$ & \\
\hline
\end{tabular}

\section{References Cited}

Ammerman, A. J., and Feldman, M. W. (1974). On the "making" of an assemblage of stone tools. American Antiquity 39:610-616.

Anderson, D. (1982). Space use and site structure. Haliksa'i 1:120-141.

Ascher, R. (1968). Time's arrow and the archaeology of a contemporary community. In Chang, K. C. (ed.), Settlement and Archaeology, National Press, Palo Alto, CA, pp. 43-52.

Bartram, L. E., Kroll, E. M., and Bunn, H. T, (1991). Variability in camp structure and bone food refuse patterning at Kua San hunter-gatherer camps. In Kroll, E. M., and Price, T. D. (eds.), The Interpretation of Archaeological Spatial Patterning, Plenum Press, New York, pp. 77-148.

Berry, K. J., Mielke, P. W., and Kvamme, K. L (1984). Efficient permutation procedures for analysis of artifact distributions. In Hietala, H. J. (ed.), Intrasite Spatial Analysis in Archaeology, Cambridge University Press, Cambridge, pp. 54-74.

Binford, L. R. (1973). Interassemblage variability: The Mousterian and the "functional argument." In Renfrew, C. (ed.), The Explanation of Culture Change: Models in Prehistory, Ducksworth, London, pp. 227-254.

Binford, L. R. (1978a). Nunamiut Ethnoarchaeology, Academic Press, New York.

Binford, L. R. (1978b). Dimensional analysis of behavior and site structure: Learning from an Eskimo hunting stand. American Antiquity 43(3):330-361.

Binford, L. R. (1980). Willow smoke and dog's tails: Hunter-gatherer settlement systems and archaeological site formation. American Antiquity 45(1):4-20.

Binford, L. R. (1981a). Behavioral archaeology and the "Pompeii premise," Journal of Anthropological Research 37(3): 195-208.

Binford, L. R. (1981b). Bones; Ancient Men and Modern Myths. Academic Press, New York.

Binford, L. R. (1982). The archaeology of place. Journal of Anthropological Archaeology 1:5-40.

Binford, L. R. (1983). In Pursuit of the Past. Thames and Hudson, London.

Binford, L. R. (1987). Researching ambiguity: Frames of reference and site structure. In Kent, S. (ed.), Method and Theory for Activity Area Research: An Ethnoarchaeological Approach, Columbia University Press, New York, pp. 449-512.

Binford, L. R. (1991). When the going gets tough, the tough get going: Nunamiut local groups, camping patterns and economic organization. In Gamble, C. S. and Boismier, W. A. (eds.), Ethnoarchaeological Approaches to Mobile Campsites, International Monographs in Prehistory, Ethnoarchaeology Series 1, pp. 25-137.

Binford, L. R., and Binford, S. R. (1966). A preliminary analysis of functional variability in the Mousterian of Levallois facies. In Clark, J. D. and Howell, F. C. (eds.) Recent Studies in Paleoanthropology, American Anthropologist 68:238-295.

Blankholm, H. P. (1991). Intrasite Spatial Analysis in Theory and Practice. Aarhus University Press, Aarhus.

Brooks, D. R., and Wiley, E. O. (1988). Evolution as Entropy: Towards a Unified Theory of Biology, 2nd ed., University of Chicago Press, Chicago. 
Carr, C. (1984). The nature of organization of intrasite archaeological records and spatial analytic approaches to their investigation. Advances in Archaeological Method and Theory 7:103-222.

Carr, C. (1985). Alternative models, alternative techniques: "Variable approaches to intrasite spatial analysis. In Carr, C. (ed.), For Concordance in Archaeological Analysis: Bridging Data Structure, Quantitative Technique, and Theory, Westport, Kansas City, MO, pp. 302473.

Carr, C. (1987). Dissecting intrasite artifact palimpsests using Fourier methods. In Kent, S. (ed.), Method and Theory for Activity Area Research: An Ethnoarchaeological Approach, Columbia University Press, New York, pp. 236-291.

Deal, M. (1985). Household pottery disposal in the Maya Highlands: An ethnoarchaeological interpretation. Journal of Anthropological Archaeology 4:243-291.

DeBoer, W. R., and Lathrap, D. W. (1979). The making and breaking of Shipibo-Conibo ceramics. In Kramer, C. (ed.), Ethnoarchaeology: Implications of ethnography for archaeology, Columbia University Press, New York, pp. 102-138.

Dekin, A. A., Jr. (1976). Elliptical analysis: An heuristic technique for the analysis of artifact clusters. In Maxwell, M. S. (ed.), Eastern Arctic Prehistory: Paleoeskimo Problems, Memoir No. 31, Society for American Archaeology, pp. 79-88.

Ebert, J. I. (1992). Distributional Archaeology, University of New Mexico Press, Albuquerque.

Eddy, F. W., Oberlin, R. E., and Farmer, T. R. (1984). Spatial analysis of archaeological data at the John Martin Dam and Reservoir, Southeastern Colorado. Plains Anthropologist 29-103:25-40.

Enloe, J. G., David, F., and Hare T. S. (1994). Patterns of faunal processing at Section 27 of Pincevent: The use of spatial analysis and ethnoarchaeological data in the interpretation of archaeological site structure. Journal of Anthropological Archaeology 13:105-124.

Farizy, C. (1994). Spatial patterning of Middle Paleolithic sites. Journal of Anthropological Archaeology 13:153-160.

Ferring, C. R. (1984). Intrasite spatial patterning: Its role in settlement-subsistence systems analysis. In Heitala, H. J. (ed.), Intrasite Spatial Analysis in Archaeology, Cambridge University Press, Cambridge, pp. 116-126.

Fisher, J. W., Jr., and Strickland, H. C. (1989). Ethnoarchaeology among the Efe Pygmies, Zaire: Spatial organization of campsites. American Journal of Physical Anthropology 78:473-484.

Fuchs, C., Kaufman, D., and Ronen, A. (1977). Erosion and artifact distribution in open-air Epi-Paleolithic sites on the coastal plain of Israel. Journal of Field Archaeology 4:171-181.

Gamble, C. (1991). An introduction to the living spaces of mobile peoples. In Gamble, C. S., and Boismier, W. A. (eds.), Ethnoarchaeological Approaches to Mobile Campsites, International Monographs in Prehistory. Ethnoarchaeology Series 1, pp. 1-23.

Gargett, R., and Hayden, B. (1991). Site, structure, kinship, and sharing in aboriginal Australia: Implications for archaeology. In Kroll, E. R. and Price, T. D. (eds.), The Interpretation of Archaeological Spatial Patterning, Plenum Press, New York, pp. 11-32.

Gifford-Gonzalez, D. P., Damrosch, D. B., Damrosch, D. R., Pryor, J., and Thunen, R. L. (1985). The third dimension in site structure: An experiment in trampling and vertical dispersal. American Antiquity 50:803-818.

Gladfelter, B. G., and Tiedemann, C. E. (1985). The contiguity-anomaly technique for analysis of spatial variation. In Carr, C. (ed.), For Concordance in Archaeological Analysis: Bridging Data Structure, Quantitative Technique, and Theory, Westport, Kansas City, MO, pp. 474-501.

Gonzalez, R. C, and Wintz, P. (1987). Digital Image Processing 2nd ed., Addison-Wesley, Reading, MA.

Graham, I. (1980). Spectral analysis and distance methods in the study of archaeological distributions. Journal of Archaeological Science 7:105-129.

Graham, M., Raish, C, and Sebastian, L. (1982). Site structure and Nunamiut ethnoarchaeology. Haliksa'i: UNM Contributions to Anthropology 1:110-119.

Grimm, L. T., and Koetje, T. A. (1992). Spatial patterns in the Upper Perigordian at Solvieux: Implications for activity reconstruction. In Hofman, J. L, and Enloe, J. E. (eds.), Piecing Together 
the Past: Applications of Refitting Studies in Archaeology. BAR International Series 578, Oxford, pp. 264-286.

Hayden, B., and Cannon, A. (1983). Where the garbage goes: Refuse disposal in the Maya Highlands. Journal of Anthropological Archaeology 2:117-163.

Hitchcock, R. K. (1982). The Ethnoarchaeology of Sedentism: Mobility Strategies and Site Structure Among Foraging and Food Producing Populations in the Eastern Kalahari Desert, Botswana, Unpublished Ph.D. dissertation, Department of Anthropology, University of New Mexico, Albuquerque.

Hitchcock, R. K. (1987). Sedentism and site structure: Organizational changes in Kalahari Baswara residential locations. In Kent, S. (ed.), Method and Theory for Activity Area Research An Ethnoarchaeological Approach, Columbia University Press, New York, pp. 374-423.

Hivernel, F., and Hodder, I. (1984). Analysis of artifact distribution at Ngenya (Kenya): Depositional and post-depositional effects. In Hietala, H. J. (ed.), Intrasite Spatial Analysis in Archaeology, Cambridge University Press, Cambridge, pp. 97-115.

Hodder, I. (1987). The meaning of discard: Ash and domestic space in Baringo. In Kent, S. (ed.), Method and Theory for Activity Area Research An Ethnoarchaeological Approach, Columbia University Press, New York, pp. 424-448.

Hodder, I., and Orton, C. (1976). Spatial Analysis in Archaeology. Cambridge University Press, Cambridge.

Janes, R. R. (1983). Archaeological Ethnography Among the Mackenzie Basin Dene, Canada, University of Calgary, Arctic Institute of North America Technical Paper No. 28, Calgary, Alberta.

Johnson, I. (1984). Cell frequency recording and analysis of artifact distributions. In Hietala, H. J. (ed.), Intrasite Spatial Analysis in Archaeology, Cambridge University Press, Cambridge, pp. 75-96.

Jones, G. T, and Beck, C. (1992). Chronological resolution in distributional archaeology. In Rossignol, J., and Wandsnider, L. (eds.), Space, Time, an Archaeological Landscapes, Plenum Press, New York, pp. 167-192.

Keeley, L. H. (1991). Tool use and spatial patterning: Complications and solution. In Kroll, E. M., and Price, T. D. (eds.), The Interpretation of Archaeological Spatial Patterning, Plenum Press, New York, pp. 257-268.

Kent, S. (1987). Understanding the use of space: An ethnoarchaeological approach. In Kent, S. (ed.), Method and Theory for Activity Area Research An Ethnoarchaeological Approach, Columbia University Press, New York, pp. 1-62.

Kent, S. (1991). The relationship between mobility strategies and site structure. In Kroll, E. M., and Price, T. D. (eds.) The Interpretation of Archaeological Spatial Patterning, Plenum Press, New York, pp. 33-60.

Kent, S. (1992). Studying variability in the archaeological record: An ethnoarchaeological model for distinguishing mobility patterns. American Antiquity 57(4):635-660.

Killion, T. W. (1992). Residential ethnoarchaeology and ancient site structure. In Killion, T. W. (ed.), Gardens of Prehistory. University of Alabama Press, Tuscaloosa, pp. 119-149.

Kind, C.-J. (1985). Die Verteilung von Steinartefakten in Grabungsflächen: Ein Modell zur Organisation Alt- und Mittelsteinzeitlicher Siedlungsplätze. Archaeologica Venatoria 7, Tübingen.

Kintigh, K. W., and Ammerman, A. J. (1982). Heuristic approaches to spatial analysis in archaeology. American Antiquity 47(1):31-63.

Kneebone, R. R. (1990). Energy Flow, Spatial Organization, and Community Structure at Matacapan, Veracruz, Mexico. Unpublished Ph.D. Dissertation, University of New Mexico, Albuquerque.

Koetje, T. A. (1987). Spatial Patterns in Magdalenian Open Air Sites from the Isle Valley, Southwestern France, BAR International Series 346, Oxford.

Koetje, T. A. (1990). Dealing with three dimensional site structure: An example using simulated archaeological levels, and the Magdalenian site of Le Flageolet II (Dordogne, France). Journal 
of Field Archaeology 18:187-198.

Koetje, T. A. (1994). Intrasite spatial structure in the European Upper Paleolithic: Evidence and patterning from the SW of France. Journal of Anthropological Archaeology 13:161-169.

Kroll, E. M., and Isaac, G.I.I. (1984). Configurations of artifacts and bones at early Pleistocene sites in East Africa. In Hietala, H. J. (ed.), Intrasite Spatial Analysis in Archaeology, Cambridge University Press, Cambridge, pp. 4-31.

Kroll, E. M., and Price, T. D. (eds.) (1991). The Interpretation of Archaeological Spatial Patterning. Plenum Press, New York.

Krzyzak, A., Kasvand, T., and Suen, C. Y. (eds.) (1989). Computer Vision and Shape Recognition, Series in Computer Science Vol. 14, World Scientific, London.

Lang, S. A. (1992). An investigation of image processing techniques at Pincevent habitation No. 1, a late Magdalenian site in northern France, Arizona State University Anthropological Research Papers No. 43, Tempe.

MacEachren, A. M. (1982). Map complexity: Comparison and measurement. The American Cartographer 9(1):31-46.

Metcalfe, D., and Heath, K. M. (1990). Microrefuse and site structure: The hearths and floors of the Heartbreak Hotel. American Antiquity 55(4):781-796,

Monmonier, M. S. (1974). Measures of pattern complexity for choroplethic maps. The American Cartographer 1(2):159-169.

Montet-White, A., and Williams, J. T. (1994). Spatial organization at a winter campsite of the last glacial maximum: The case of Grubgraben AL1. Journal of Anthropological Archaeology 13:125-138.

Murray, P. (1980). Discard location: The ethnographic data. American Antiquity 45:490-502.

Newell, R. R., and Dekin, A. A., Jr. (1978). An integrative strategy for the definition of behaviorally meaningful archaeological units. Palaeohistoria 20:8-38.

O'Connell, J. F. (1987). Alyawara site structure and its archaeological implications. American Antiquity 52(1):74-108.

O'Connell, J. F. (1993). What can Great Basin archaeologists learn form the study of site structure? An ethnoarchaeological perspective. Utah Archaeology 1993:7-26.

O'Connell, J. F. (1995). Ethnoarchaeology needs a general theory of behavior. Journal of Archaeological Research 3(3):205-255.

O'Connell, J. F., Hawkes, K., and Jones, N. B. (1991). Distribution of refuse-producing activities at Hazda residential camps. In Kroll, E. M., and Price, T. D., The Interpretation of Archaeological Spatial Patterning, Plenum Press, New York, pp. 61-76.

Orton, C. R. (1982). Stochastic process and archaeological mechanism in spatial analysis. Journal of Archaeological Science 9:1-23.

Petraglia, M. D., Akoshima, K., and Straus, L. G. (1994). Interpreting the formation of the Abri Dufaur: An Upper Paleolithic site in southwestern France. Journal of Anthropological Archaeology 13:139-151.

Prigogine, I. (1980). From Being to Becoming: Time and Complexity in the Physical Sciences. W. H. Freeman, San Francisco.

Rapson, D. J., and Todd, L. C. (1992) Conjoins, contemporaneity, and site structure: Distributional analysis of the Bugas-Holding site. In Hofman, J. L, and Enloe, J. E. (eds.), Piecing Together the Past: Applications of Refitting Studies in Archaeology. BAR International Series 578, Oxford, pp. 238-263.

Reid, J. J., Schiffer, M. B., and Rathje, W. L. (1975). Behavioral archaeology: Four strategies. American Anthropologist 77:864-869.

Rick, J. (1976). Downslope movement and archaeological intrasite spatial analysis. American Antiquity 41:133-144.

Rigaud, J.-P, and Simek, J. F. (1991). Interpreting spatial patterns at the Grotte XV: A multiplemethod approach. In Kroll, E. M., and Price, T. D. (eds.), The Interpretation of Archaeological Spatial Patterning, Plenum Press, New York, pp. 199-220. 
Rogers, A. (1982). Data collection and information loss in the study of spatial pattern. World Archaeology 14(2):249-258.

Rogers, A., and Chasko, W. J., Jr., (1979). The spatial distribution of archaeological sites: A clue to subsistence behavior. In Biella, J. V. and Chapman, R. C. (eds.) Archaeological Investigations in Cochiti Reservoir, New Mexico. Vol 4. Adaptive Change in the Northern Rio Grande Valley, Office of Contract Archaeology, University of New Mexico, Albuquerque, pp. 283-294.

Rossignol, J. (1992). Concepts, methods and theory building: A landscape approach. In Rossignol, J. and Wandsnider, L. (eds.), Space, Time, and Archaeological Landscapes, Plenum Press, New York, pp. 3-20.

Rossignol, J., and Wandsnider, L. (1992). Space, Time, and Archaeological Landscapes. Plenum Press, New York.

Schiffer, M. B. (1972). Archaeological context and systemic context. American Antiquity 37(2):156-165.

Schiffer, M. B. (1974). On Whallon's use of dimensional analysis of variance at Guila Naquitz. American Antiquity 39:490-492.

Schiffer, M. B. (1976). Behavioral Archeology. Academic Press, New York.

Schiffer, M. B. (1983). Toward the identification of formation processes. American Antiquity 48(4):675-706.

Schiffer, M. B. (1987). Formation Processes of the Archaeological Record. University of New Mexico Press, Albuquerque.

Schiffer, M. B. (1988). The structure of archaeological theory. American Antiquity 53:461-485.

Segen, J. (1989). From features to symbols: Learning relational models of shape. In Simon, J. C. (ed.), From Pixels to Features, North-Holland, Amsterdam.

Seymour, D., and Schiffer, M. B. (1987). A preliminary analysis of pithouse assemblages from Snaketown, Arizona. In Kent, S. (ed.), Method and Theory for Activity Area Research: An Ethnoarchaeological Approach, Columbia University Press, New York, pp. 549-603.

Simek, J. (1984). A K-Means Approach to the Analysis of Spatial Structure in Upper Paleolithic Habitation Sites: Le Flageolet I and Pincevent Section 36, BAR International Series 205, Oxford.

Simek, J. F., and Larick, R. R. (1983). The recognition of multiple spatial patterns: A case study from the French Upper Paleolithic. Journal of Archaeological Science 10:165-180.

Simms, S. R. (1988). The archaeological structure of a Bedouin camp. Journal of Archaeological Science 15:197-211.

Simms, S. R. (1989). The structure of the Bustos Wickiup Site, eastern Nevada. California and Great Basin Anthropology 11(1):2-34.

Simms, S. R., and K. M. Heath (1990). Site structure of the Orbit Inn: An application of ethnoarchaeology. American Antiquity 55(4):797-812.

Simon, J. C. (ed.) (1989). From Pixels to Features, North-Holland, Amsterdam.

Smith, C. S., McNees, L. M., and Reust, T. P. (1995). Site structure of two buried stone circle sites, southern Wyoming, Plains Anthropologist 40-151:5-22.

Spear, L. M. (1979). The applicability of statistical mapping as an initial step in the spatial analysis of archaeological distributions. In Biella, J. V., and Chapman, R. C. (eds.), Archaeological Investigations in Cochiti Reservoir, New Mexico. Vol 4: Adaptive Change in the Northern Rio Grande Valley, Office of Contract Archaeology, University of New Mexico, Albuquerque, pp. 319-338.

Speth, J. D., and Johnson, G. A. (1976). Problems in the use of correlation for the investigation of tool kits and activity areas. In Cleland, C. (ed.), Culture Changes and Continuity: Essays in Honor of James Bennett Griffin, Academic Press, London, pp. 35-57.

Spurling, B., and Hayden, B. (1984). Ethnoarchaeology and intrasite spatial analysis: A case study from the Australian Western Desert. In Hietala, H. J. (ed.), Intrasite Spatial Analysis in Archaeology, Cambridge University Press, Cambridge, pp. 224-241.

Stein, J. K. (1987). Deposits for archaeologists. Advances in Archaeological Method and Theory 11:337-395. 
Stevenson, M. G. (1982). Toward an understanding of site abandonment behavior: Evidence from historic mining camps in the southwest Yukon. Journal of Anthropological Archaeology 1:237-265.

Stevenson, M. G. (1985). The formation of artifact assemblages at workshop/habitation sites: Models from Peace Point in northern Alaska. American Antiquity 50(1):63-81.

Stevenson, M. G. (1991). Beyond the formation of hearth-associated artifact assemblages. In Kroll, E. M., and Price, T. D. (eds.), The Interpretation of Archaeological Spatial Patterning, Plenum Press, New York, pp. 269-300.

Stockton, E. D. (1973). Shaw's Creek Shelter: Human displacement of artefacts and its significance. Mankind 9:112-117.

Sullivan, A. P. (1992a). Investigating the archaeological consequences of short-duration occupations. American Antiquity 57:99-115.

Sullivan, A. P. (1992b). The role of theory in solving enduring archaeological problems. In Wandsnider, L. (ed.), Quandaries and Quests: Visions of Archaeology's Future, Center for Archaeological Investigations, Occasional Paper No. 20, Southern Illinois University, Carbondale, pp. 239-253.

Tipps, B. L. (1993). Investigation of the spatial structure of lithic scatter sites from an ethnoarchaeological perspective: Examples from Utah and Nevada. Utah Archaeology 1993:57-71.

Wandsnider, L. (1989). Long-term Land Use, Formation Processes, and the Structure of the Archaeological Landscape: A Case Study from Southwestern Wyoming. University Microfilms, Ann Arbor, MI.

Wandsnider, L. (1992). The spatial dimension of time. In Rossignol, J., and Wandsnider, L. (eds.), Space, Time, and Archaeological Landscapes, Plenum Press, New York, pp. 257-281.

Wandsnider, L. (1995). The results of education: Natural formation research and sealer analysis of archaeological deposits. In: Quaternary Environments and Geoarchaeology of India: Essays in Honour of Professor S. N. Rajaguru, Geological Society of India Memoir 32, pp. 435-445.

Wandsnider, L. (1996). Landscape element configuration, lifespace, and occupation history: Ethnoarchaeological observations and archaeological applications. In Sullivan, A. P. (ed.), The Interpretative Potential of Surface Archaeological Phenomena, University of New Mexico Press, Albuquerque (in press).

Whallon, R. (1973). Spatial analysis of occupation floors. I. Applications of dimensional analysis of variance. American Antiquity 38:320-328.

Whallon, R. (1974). Spatial analysis of occupation floors. II, The application of nearest neighbor analysis. American Antiquity 39:16-344.

Whallon, R. (1978). The spatial analysis of Mesolithic occupation floors. In Mellars, P. (ed.), The Early Postglacial Settlement of Northern Europe, University of Pittsburgh Press, Pittsburgh, pp. 27-36.

Whallon, R. (1984). Unconstrained clustering for the analysis of spatial distributions in archaeology. In Hietala, H. J. (ed.), Intrasite Spatial Analysis in Archaeology, Cambridge University Press, Cambridge, pp. 242-277.

Whitelaw, T. (1991). Some dimensions of variability in the social organization of community space among foragers. In Gamble, C. S., and Boismier, W. A. (eds.), Ethnoarchaeological Approaches to Mobile Campsites, International Monographs in Prehistory. Ethnoarchaeology Series 1, pp. 139-188.

Wylie, A. (1989). Archaeological cables and tacking: The implications of practice for Bernstein's "Options Beyond Objectivism and Relativism." Philosophy of the Social Sciences 18:1-18.

Wylie, A. (1992). The interplay of evidential constraints and political interests: Recent archaeological research on gender. American Antiquity 57(1):15-35.

Yellen, J. E. (1977). Archaeological Approaches to the Present: Models for Reconstructing the Past, Academic Press, New York.

Yellen, J. E. (1991). Small mammals: Post-discard patterning of !Kung San faunal remains. Journal of Anthropological Archaeology 10:152-192. 